\title{
Cuestiones jurídicas sobre el papel de los entes locales en la transición energética: hacia la producción y el consumo del hidrógeno renovable 1
}

\section{Legal issues on the role of local authorities in the energy transition: going to the production and consumption of renewable hydrogen}

\author{
Carmen María Ávila Rodríguez \\ Universidad de Málaga (España) \\ ORCID: https://orcid.org/0000-0002-7225-9324 \\ cmavila@uma.es
}

\begin{abstract}
NOTA BIOGRÁFICA
Doctora en Derecho y Premio Extraordinario de Doctorado por la Universidad de Málaga. Profesora Titular de Derecho Administrativo de la Universidad de Málaga desde 2017. Ha realizado estancias de investigación en el Center Constitucional Studies and Democrátic Development (CCSDD); el Dipartimento di Scienze Giuruduche «A. Cicu» de la Universita' di Bologna y en el Leicester Law School (University of Leicester). Es subdirectora académica de la Revista Jurídica de Investigación e Innovación Educativa (REJIE Nueva época) de la Universidad de Málaga y colaboradora permanente de la Sección de Energía de la Revista General de Derecho de los Sectores Regulados de lustel.

Ha participado en distintos proyectos de investigación nacionales en materia de Energía, Medio Ambiente, Ordenación del Territorio y Urbanismo. Ha participado en distintos proyectos autonómicos andaluces, entre ellos proyecto de apoyo documental y técnico a la Sala de lo Contencioso Administrativo del Tribunal Superior de Justicia de Andalucía con sede en Málaga. Ha colaborado durante años con la Oficina del Defensor del Ciudadano/a de la Diputación de Málaga.

Es autora de múltiples publicaciones (libros, capítulos de libros, artículos de revistas, actas de congresos) en materias sobre Energía, Transportes, Medio Ambiente, Protección de Datos, Buena Administración, Ordenación del Territorio y Defensores del Pueblo. Su actividad investigadora es compaginada con su actividad docente, impartiendo docencia en materias regladas tanto a nivel de grado como de posgrado en distintas titulaciones.
\end{abstract}

\section{RESUMEN}

La tecnología del hidrógeno está demostrando cada día que es posible producir y consumir hidrógeno renovable. La Unión Europea, consciente de ello, quiere situarse como líder en este objetivo de transformación de nuestra economía en una economía descarbonizada. El presente estudio hace un análisis de las estrategias que han sido aprobadas a nivel comunitario y estatal, así como de las reformas normativas necesarias para que las Administraciones, especialmente la Administración local sea impulsora del uso doméstico y comercial del hidrógeno renovable.

\section{PALABRAS CLAVE}

Hidrógeno renovable; hidrógeno verde; Administración local; movilidad sostenible; autoconsumo y comunidades energéticas locales.

1 Este comentario se realiza en el marco del Proyecto: "Sostenibilidad energética y entes locales: incidencia del nuevo paquete energético de la Unión Europea” (Ref. DER2017-86637-C3-2-P B). Ministerio de Ciencia, Innovación y Universidades. 
REALA. Nueva Época - N.o 16, octubre 2021 - ISSN: 1989-8975 - DOI: https://doi.org/10.24965/reala.i16.10952 - [Págs. 71-97]

Cuestiones jurídicas sobre el papel de los entes locales en la transición energética: hacia la producción y el consumo del..

\begin{abstract}
Hydrogen technology is proving every day that it is possible to produce and consume renewable hydrogen. The European Union takes a leading role in this goal to transform our economy into a decarbonized economy. This paper analyzes the strategies that have been approved by the European Union and the Spanish State to promote renewable hydrogen. Necessary regulatory reforms are also analyzed by this paper, to argue that public Administrations, especially local Administrations, can take a leading role in promoting the domestic and commercial use of renewable hydrogen.
\end{abstract}

\title{
KEYWORDS
}

Green hydrogen; renewable hydrogen; local Administration; sustainable mobility; electrical self-consumption and local energy communities.

\begin{abstract}
SUMARIO
1. BREVE INTRODUCCIÓN: LA CADENA DE VALOR DEL HIDRÓGENO RENOVABLE. 2. CONFUSIÓN TERMINOLÓGICA PARA REFERIRSE AL HIDRÓGENO. 3. NECESIDAD DE UN MARCO NORMATIVO EUROPEO PARA EL IMPULSO DEL HIDRÓGENO RENOVABLE. 4. BARRERAS NORMATIVAS NACIONALES A SUPERAR PARA IMPULSAR EL HIDRÓGENO RENOVABLE 5. LA ADMINISTRACIÓN LOCAL COMO SUJETO PROACTIVO EN LA TRANSICIÓN ENERGÉTICA. 5.1. COMPETENCIAS PROPIAS DE LOS MUNICIPIOS PARA IMPULSAR EL HIDRÓGENO RENOVABLE: PRESTACIÓN DE SERVICIOS OBLIGATORIOS RELACIONADOS CON LA MOVILIDAD SOSTENIBLE, LA ILUMINACIÓN EXTERIOR Y EL SANEAMIENTO DE AGUAS RESIDUALES. 5.2. LA RESPONSABILIDAD PROACTIVA DE LA ADMINISTRACIÓN LOCAL: AUTOCONSUMO, CONTRATACIÓN VERDE Y COMUNIDADES ENERGÉTICAS LOCALES: A) Incremento del autoconsumo de energías renovables de la Administración local y la posibilidad de producir hidrógeno renovable. B) El impulso de la contratación pública ecológica. C) Iniciativas para constituir comunidades energéticas locales. 6. A MODO DE COROLARIO. REFERENCIAS BIBLIOGRÁFICAS.
\end{abstract}

«Sí, amigo mío -repuso Ciro Smith-; (...) creo que el agua se usará un día como combustible, que el hidrógeno y el oxígeno que la constituyen, utilizados aislada y simultáneamente, producirán una fuente de calor y de luz inagotable y de una intensidad mucho mayor que la de la hulla. El agua es el carbón del porvenir».

La isla misteriosa. Julio Verne. 1874.

\section{BREVE INTRODUCCIÓN: LA CADENA DE VALOR DEL HIDRÓGENO RENOVABLE}

Podemos imaginar que Julio Verne, que para escribir sus obras se basaba en revistas científicas, tuvo un sueño premonitorio: las potencialidades del hidrógeno que hoy afirmamos, coloquialmente, que está de moda. Así se puede afirmar tras la aprobación de la Comunicación de la Comisión al Parlamento Europeo, al Consejo, al Comité Económico y Social Europeo y al Comité de las Regiones, Una estrategia del hidrógeno para una Europa climáticamente neutra y la Hoja de ruta del hidrógeno: una apuesta por el hidrógeno renovable, elaborada por el Gobierno de España.

Adentrémonos, brevemente, en la cadena de valor del hidrógeno. El hidrógeno es el elemento más abundante en el universo, pero no puede tomarse directamente de la naturaleza, no es una fuente de energía primaria, por ello se tiene que fabricar o producir. Además, se encuentra combinado con otros elementos como el oxígeno formando moléculas de agua, o al carbono, formando compuestos orgánicos.

Hoy en día se produce hidrógeno, pero esta producción es muy contaminante, pues se basa en un proceso de reformado de combustibles, mayormente teniendo como materia prima el carbón, la biomasa o el biogás, la energía nuclear o la electricidad de la red. También, mediante procesos de reformado de gas natural u otros hidrocarburos ligeros como metano o gases licuados de petróleo, siendo, actualmente, éste el $99 \%$ del hidrógeno consumido en España. La tendencia actual de la política europea ha quedado reflejada en la Comunicación de la Comisión al Parlamento Europeo, al Consejo, al Comité Económico y Social Europeo y al Comité de las Regiones, Una estrategia del hidrógeno para una Europa climáticamente neutra. Ésta 
REALA. Nueva Época - N.o 16, octubre 2021 - ISSN: 1989-8975 - DOI: https://doi.org/10.24965/reala.i16.10952 - [Págs. 71-97]

Cuestiones jurídicas sobre el papel de los entes locales en la transición energética: hacia la producción y el consumo del...

Carmen María Ávila Rodríguez

tiene como objetivo la producción transitoria de hidrógeno a partir de gas natural e hidrocarburos ligeros, pero al que se le aplican técnicas de captura, uso y almacenamiento de carbono (CCUS: Carbon Capture, Utilization and Storage) lo que permite reducir hasta en un $95 \%$ las emisiones de $\mathrm{CO}_{2}$ generadas durante el proceso para llegar, de manera definitiva, a la producción de hidrógeno mediante el proceso de electrolisis, a partir de fuentes renovables tales como la eólica, la geotérmica, la solar y la hídrica e inclusive la energía de las olas y mareomotriz que prácticamente no produce gases de efecto invernadero. Éste sería el hidrógeno renovable.

En cuanto al emplazamiento de la planta de producción de hidrógeno renovable, es interesante señalar que puede ser producido en grandes instalaciones centrales o localmente en pequeñas unidades distribuidas ubicadas en o cerca del punto de uso. Esto significa que todas las zonas, incluso áreas remotas, pueden convertirse en productores de energía.

Una vez producido, el hidrógeno renovable actúa como un vector energético casi perfecto porque su potencial reside en almacenar y portar en forma química energía de fuentes renovables que no puede ser acumulada. A modo de ejemplo, la energía solar puede ser usada directamente para calentar o para generar electricidad, pero la electricidad tiene que ser consumida instantáneamente; en cambio, si la electricidad, generada de la energía solar, se utiliza para producir hidrógeno renovable, éste se puede almacenar para ser consumido posteriormente liberando energía sin contaminar el ambiente.

Los usos finales del hidrógeno renovable son muy diversos. En su forma natural se puede usar directamente como combustible, como materia prima en la industria y como vector energético. La aplicación del hidrógeno renovable en el sector del transporte se materializa en el uso de pilas de combustible de hidrógeno, que son dispositivos en los que se utiliza el hidrógeno producido a partir de fuentes renovables para generar electricidad, aportando la fuerza motriz para movilizar los vehículos. Estas pilas de combustible suelen instalarse en combinación con baterías eléctricas que se auto recargan durante el funcionamiento del vehículo mediante frenada regenerativa. En el transporte por carretera esta modalidad incluye tanto los vehículos ligeros (turismos y furgonetas), como los vehículos pesados (camiones y autobuses). En el transporte ferroviario se utiliza como principal recurso energético la energía eléctrica, si bien todavía existen vías sin electrificar con trenes propulsado por locomotoras diésel. En este último nicho y, concretamente cuando la electrificación no sea viable, es donde las pilas de combustible alimentadas por hidrógeno renovable pueden tener una clara aplicación. En el transporte marítimo la aplicación del hidrógeno renovable abarca no solo la utilización de pilas de combustible en embarcaciones, sino también en la maquinaria empleada en los puertos y terminales de carga. En relación con las embarcaciones, actualmente, el empleo de pilas de combustible para el transporte marítimo se limita a proyectos de demostración en pequeños buques, pero se espera su análisis de viabilidad en grandes embarcaciones. En el transporte aéreo se espera que las pilas de combustible constituyan una alternativa como carburante para aeronaves y para la maquinaria empleada en los aeropuertos y terminales de carga. Además, existen otras opciones para la aplicación del hidrógeno en aviación, como la fabricación de queroseno sintético a base de hidrógeno renovable.

Respecto al uso residencial y en los servicios, el hidrógeno renovable se posiciona como una de las alternativas para contribuir a la descarbonización del sector doméstico y terciario, gracias a su capacidad de proporcionar un suministro energético flexible. Esta descarbonización se concretaría en la sustitución de los elementos de calefacción eléctricos y las calderas de gas natural por calderas de hidrógeno renovable.

En el sector industrial destacan tres campos de aplicación. Por un lado, en la industria de refino dedicada a procesos de eliminación de impurezas del petróleo crudo o de mejora de los crudos más pesados en sus usos como materia prima. Por otro lado, en la industria química que lo utiliza como materia prima para la elaboración de productos químicos, especialmente amoniaco y metanol, que requieren de elevadas cantidades del mismo, y que a su vez sirven como fuente para la producción de otros compuestos químicos tales como fertilizantes, biocombustibles o plásticos. Y, finalmente, en la industria metalúrgica para la elaboración de ciertas aleaciones tales como el acero para la que se necesitan grandes aportes energéticos, y en la que se puede emplear el hidrógeno renovable como fuente energética para alcanzar las temperaturas requeridas en su proceso de producción (altos hornos). También puede ser utilizado como agente reductor para la generación de aleaciones, desplazando el uso de carbón ${ }^{2}$.

2 Vid. Ministerio para la transición ecológica y el reto demográfico (2020, pp. 19-23) y Ávila (2021). 
Hoy en día, el hidrógeno representa menos del $2 \%$ del consumo de energía en Europa ${ }^{3}$ y se produce casi exclusivamente con el uso constante de combustibles fósiles. Para la Unión Europea, el hidrógeno renovable tiene un papel importante que desempeñar a la hora de reducir las emisiones en los sectores de difícil descarbonización. El hidrógeno producido mediante electrolisis con electricidad renovable puede desempeñar un papel «nodal» particularmente importante en un sistema energético integrado, pues puede aportar eficiencia en la medida en que puede integrar grandes porcentajes de generación variable de energías renovables, descargando las redes en períodos de abundante oferta, y proporcionando almacenamiento a largo plazo para el sistema energético. También permite utilizar la producción local de electricidad renovable en una gama de aplicaciones de uso final adicionales ${ }^{4}$.

En la actualidad, ni el hidrógeno renovable ni el hidrógeno a partir de combustibles fósiles con bajas emisiones de carbono son competitivos en términos de costes con el hidrógeno a partir de combustibles fósiles ${ }^{5}$, pero el panorama está cambiando porque los costes del hidrógeno renovable están bajando rápidamente ${ }^{6}$. Los costes de los electrolizadores ya se han reducido en un $60 \%$ en los últimos diez años y se espera que se reduzcan a la mitad en 2030 en comparación con los de hoy gracias a las economías de escala. En regiones en las que la electricidad renovable es barata, se espera que los electrolizadores puedan competir con el hidrógeno a partir de combustible fósiles en $2030^{7}$.

Es interesante señalar que recientemente se ha publicado la noticia de que la empresa estadounidense Cummins ubicará en Guadalajara una de las mayores plantas de electrolizadores para la producción de hidrógeno verde en el mundo tras sellar un acuerdo con Iberdrola. Esta alianza sitúa a Cummins como proveedor de sistemas de electrolizadores para proyectos a gran escala en estos EEUU y España y a Iberdrola como desarrollador de proyectos de electrolizadores y proveedor de hidrógeno renovable para clientes industriales ${ }^{8}$. O también la noticia de que bp, Iberdrola y Enagás han alcanzado un acuerdo para evaluar la instalación de un electrolizador de 20 MW para la generación de hidrógeno verde en los terrenos propiedad de bp en el polígono industrial donde se ubican sus instalaciones. El electrolizador funcionaría con energía renovable producida, entre otras fuentes de generación, por una planta fotovoltaica de 40 MW. Con la trascendencia de que la refinería de bp en Castellón es el mayor productor y consumidor de hidrógeno de la Comunidad Valenciana. El resultado de este proyecto permitiría reemplazar el hidrógeno gris, que la refinería utiliza en sus procesos para producir biocombustibles, por hidrógeno verde 9 .

\section{CONFUSIÓN TERMINOLÓGICA PARA REFERIRSE AL HIDRÓGENO}

Actualmente no existe una clasificación consensuada y uniforme sobre los tipos de hidrógeno. La comunicación de la Comisión al Parlamento Europeo, al Consejo, al Comité Económico y Social Europeo y al Comité de las Regiones, Una estrategia del hidrógeno para una Europa climáticamente neutra clasifica los tipos de hidrógeno en función de las vías de producción porque estás están asociadas a una amplia gama de emisiones, dependiendo de la tecnología y la fuente de energía utilizadas. La clasificación es la siguiente:

- Hidrógeno electrolítico que designa el hidrógeno producido mediante la electrólisis de agua (en un electrolizador alimentado por electricidad), independientemente de la fuente de electricidad. Las

3 Este dato está calculado sobre la base de los datos de producción facilitados por la Empresa Común Pilas de Combustible e Hidrógeno, incluye el hidrógeno como materia prima; Empresa Común FCH, hoja de ruta para el hidrógeno, 2019.

4 Vid. Comisión Europea (2020, p. 13).

5 Los costes estimados del hidrógeno a partir de combustibles fósiles, que dependen mucho de los precios del gas natural, y sin tener en cuenta el coste de las emisiones de $\mathrm{CO}_{2}$, se sitúan en torno a 1,5 EUR/kg para la UE Los costes estimados del hidrógeno a partir de combustibles fósiles con captura y almacenamiento de carbono son de unos $2 \mathrm{EUR} / \mathrm{kg}$, y los del hidrógeno renovable de entre $2,5 \mathrm{y}$ $5,5 \mathrm{EUR} / \mathrm{kg}$. Estos datos se extraen del Informe sobre el hidrógeno 2019 de la AIE (p. 42), y sobre la base de las hipótesis de precios de la AIE para la UE: 22 EUR/MWh para el gas natural, entre 35 y 87 EUR/MWh para la electricidad y costes de capacidad de $600 \mathrm{EUR} / \mathrm{kW}$. Hoy en día, se necesitarían precios de entre 55 y 90 EUR por tonelada de $\mathrm{CO}^{2}$ para que el hidrógeno a partir de combustibles fósiles con captura de carbono fuera competitivo con respecto al hidrógeno a partir de combustibles fósiles. Sin embargo, en esta fase, los costes solo pueden estimarse, ya que en la actualidad no se ha iniciado la construcción ni la explotación de ningún proyecto de este tipo en la UE.

6 Vid. Asociación Española del Hidrógeno (IDAE) (2008).

7 Partiendo de los precios actuales del gas y la electricidad, se prevé que el hidrógeno a partir de combustibles fósiles con bajas emisiones de carbono costará en 2030 entre 2 y 2,5 EUR/kg en la UE, y el hidrógeno renovable entre 1,1 y 2,4 EUR/kg (AIE, IRENA, BNEF).

8 Noceda (2021, 24 de mayo).

9 Expansión (2021, 28 de abril). 
REALA. Nueva Época - N.o 16, octubre 2021 - ISSN: 1989-8975 - DOI: https://doi.org/10.24965/reala.i16.10952 - [Págs. 71-97]

Cuestiones jurídicas sobre el papel de los entes locales en la transición energética: hacia la producción y el consumo del...

emisiones de gases de efecto invernadero durante todo el ciclo de vida de la producción de hidrógeno electrolítico dependen de cómo se produce la electricidad utilizada.

- Hidrógeno renovable que designa el hidrógeno producido mediante la electrólisis de agua (en un electrolizador alimentado por electricidad), y con la electricidad procedente de fuentes renovables. Las emisiones de gases de efecto invernadero durante todo el ciclo de vida de la producción de hidrógeno renovable son casi cero. El hidrógeno renovable también puede producirse a través del reformado de biogás (en lugar de gas natural) o de la conversión bioquímica de biomasa2, si se cumplen los requisitos de sostenibilidad. La hoja de ruta del hidrógeno aprobada por el gobierno español se refiere a este hidrógeno como hidrógeno renovable o hidrógeno verde indistintamente.

- Hidrógeno limpio que alude al hidrógeno renovable.

- Hidrógeno a partir de combustibles fósiles que designa el hidrógeno producido mediante diversos procesos que utilizan combustibles fósiles como materia prima, principalmente, el reformado de gas natural o la gasificación de carbón. Las emisiones de gases de efecto invernadero durante el ciclo de vida de la producción de hidrógeno a partir de combustibles fósiles son elevadas. La hoja de ruta del hidrógeno aprobada por el gobierno español se refiere a este hidrógeno como hidrógeno gris cuando se produce a partir de gas natural u otros hidrocarburos ligeros como metano o gases licuados de petróleo mediante procesos de reformado. Si el hidrógeno se produce a partir de carbón, la energía nuclear o la electricidad de la red, lo denomina hidrógeno negro o marrón.

- Hidrógeno a partir de combustibles fósiles con captura de carbono que es una subparte del hidrógeno a partir de combustibles fósiles, pero en la que se capturan las emisiones de gases de efecto invernadero como parte del proceso de producción de hidrógeno. Las emisiones de gases de efecto invernadero procedentes de la producción de hidrógeno a partir de combustibles fósiles con captura de carbono o pirolisis son inferiores a las del hidrógeno a partir de combustibles fósiles, pero debe tenerse en cuenta la eficacia variable de la captura de gases de efecto invernadero $(90 \%$ como máximo). La hoja de ruta del hidrógeno aprobada por el gobierno español se refiere a este hidrógeno como hidrógeno azul.

- Hidrógeno con bajas emisiones de carbono que incluye el hidrógeno a partir de combustibles fósiles con captura de carbono y el hidrógeno electrolítico, cuyas emisiones de gases de efecto invernadero durante todo el ciclo de vida son considerablemente reducidas en comparación con la producción existente de hidrógeno.

Con esta clasificación se puede afirmar que no hay un criterio claro y uniforme de clasificación del hidrógeno. Indistintamente, se denomina al hidrógeno renovable, limpio o verde en el caso del hidrógeno producido a través de la electrolisis con fuentes de energía renovable. El hidrógeno a partir de combustibles fósiles sin captura de carbono se denomina, en función del tipo de combustible como, negro (carbón), gris (gas o hidrocarburos ligeros) o marrón (energía nuclear). Y cuando se procede a la captura del carbono se denomina hidrógeno azul. En definitiva, no existe un criterio uniforme de clasificación del hidrógeno y la clasificación que existe es confusa porque se basa en colores sin seguir un criterio científico basado en el ciclo de vida de las emisiones de gases de efecto invernadero a lo largo de todo el proceso de producción y transporte del hidrógeno. En este sentido se ha pronunciado recientemente, el 19 de mayo de 2021, el Parlamento europeo en su resolución sobre la estrategia europea para el hidrógeno ${ }^{10}$. En él ha concluido que a nivel europeo es necesario hacer una clasificación jurídica común de los diferentes tipos de hidrógeno. Es necesario llegar a un acuerdo rápido sobre una terminología amplia, precisa, uniforme y de base científica en toda la Unión con el fin de adaptar las definiciones jurídicas nacionales y ofrecer una clasificación clara que aporte seguridad jurídica. Esta terminología tiene que basarse en una evaluación con base científica, alejada del enfoque basado en colores comúnmente utilizado; opina que esta clasificación debería basarse en el ciclo de vida de las emisiones de gases de efecto invernadero a lo largo de todo el proceso de producción y transporte del hidrógeno, pero también deberá tener en cuenta criterios de sostenibilidad transparentes y sólidos en consonancia con los principios de la economía circular ${ }^{11}$. El informe pone de manifiesto que incluso entre distintos agentes a nivel europeo (por ejemplo, la Comisión y la Alianza Europea por un Hidrógeno Limpio) existe una discrepancia entre las diferentes definiciones de hidrógeno limpio utilizadas, al confundir e incluir la distinción entre hidrógeno renovable y con bajas emisiones de carbono.

10 https://www.europarl.europa.eu/doceo/document/TA-9-2021-0241_ES.html\#def 117

11 Sobre la economía circular consultar los siguientes estudios recientes: Alenza (20-20, pp. 225-249) y Gudín (2019). 


\section{NECESIDAD DE UN MARCO NORMATIVO EUROPEO PARA EL IMPULSO DEL HIDRÓGENO RENOVABLE}

En noviembre de 2018 La Comisión Europea presentó la Comunicación titulada Un planeta limpio para todos. La visión estratégica europea a largo plazo de una economía próspera, moderna, competitiva y climáticamente neutra ${ }^{12}$. En esta Comunicación se confirma el compromiso de Europa de liderar la acción por el clima a escala mundial y marca como objetivo final conseguir de aquí a 2050 las cero emisiones netas de gases de efecto invernadero a través de una transición socialmente justa realizada de manera rentable. La UE no pretende iniciar nuevas políticas ni revisar los objetivos para 2030, que quedan confirmados como se fijaron originariamente, sino que su finalidad es indicar en qué dirección debe ir la política de la UE en materia de clima y energía y servir de marco a lo que la UE considera su contribución a largo plazo para lograr los objetivos de temperatura del Acuerdo de París, en consonancia con los Objetivos de Desarrollo Sostenible de las Naciones Unidas ${ }^{13}$.

La UE afirma que todos los sectores de la economía tienen un papel que desempeñar en la transición hacia la neutralidad climática. El sector energético debe desplegar totalmente el uso de energía renovable impulsando una electrificación a gran escala del sistema energético, englobando tanto a usuarios finales (industria, edificios o transporte), como a productores. De esta manera el sector eléctrico se debe convertir en un elemento central para la transformación de otros sectores económicos. El sector industrial debe reducir la emisión de gases con efecto invernadero mediante mejoras adicionales en la eficiencia y cambiando a fuentes de energía bajas y nulas en carbono, para ello se hace necesario impulsar la electrificación basada en energías renovables, la biomasa sostenible, los combustibles sintéticos o el hidrógeno renovable. El sector del transporte tiene que lograr reducciones profundas de emisiones y para ello la Unión Europea se compromete a promover la eficiencia general de los vehículos, a incentivar los vehículos y la infraestructura de bajas y cero emisiones; a hacer un viraje en relación a los combustibles fomentando el uso de combustibles alternativos y con cero emisiones de carbono; diseñar y poner en práctica una mayor eficiencia del sistema de transporte. El sector de la construcción también tiene un papel decisivo mejorando el aislamiento de los edificios y adoptando otras medidas para hacer más eficiente el parque de viviendas y reducir el uso de energía para calefacción. Para la UE el cambio de combustible debe ser una realidad en casi todos los hogares y ha de reorientarse a utilizan calefacción renovable (electricidad, calefacción urbana producida a partir de fuentes renovables, gas renovable y energía solar térmica). Para ello entiende que es importante dar un papel protagonista, entre otros gases, al hidrógeno producido a partir de electricidad renovable porque podrían ser utilizado en los edificios existentes sin cambiar la red de transmisión/distribución actual y el tipo de electrodomésticos.

En este contexto en noviembre de 2019, se aprueba por la UE el Pacto Verde Europeo como manifestación del compromiso de la Comisión Europea de responder a los desafíos del clima y el medio ambiente ${ }^{14}$. Este pacto contiene medidas concretas para transformar la UE en una sociedad equitativa y próspera, con una economía moderna, eficiente en el uso de los recursos y competitiva, en la que no habrá emisiones netas de gases de efecto invernadero en $2050^{15}$. Teniendo como marco el Pacto Verde Europeo las instituciones de la UE realizan una serie de propuestas y adoptan una serie de estrategias. Entre las primeras es oportuno destacar la propuesta de aprobar la primera Ley del Clima Europea ${ }^{16}$; la propuesta de revisar la Directiva sobre fuentes de energías renovables ${ }^{17}$; la propuesta de la revisión de la Directiva de eficiencia

12 https://eur-lex.europa.eu/legal-content/ES/TXT/PDF/?uri=CELEX:52018DC0773\&from=SL

13 Vid. Rosa (2020, pp. 41-78); Escudero y Martínez (2019).

14 https://eur-lex.europa.eu/legal-content/ES/TXT/?qid=1576150542719\&uri=COM\%3A2019\%3A640\%3AFIN

15 Sobre el Pacto Verde y la política energética de la Unión europea consultar los siguientes estudios recientes: Delgado (2011, pp. 393-456), Delgado (2020, pp. 140-174), Fernández de Gatta (2020, pp. 78-109), Martín (2020), Egea (2017, pp. 485-498), Ruiz (2012) y Ruiz (2018, págs. 265-280).

16 La propuesta de la Ley del Clima se concretó el 4 de marzo de 2020 e incluye medidas para hacer un seguimiento de los avances y ajustar las acciones europeas en consecuencia, sobre la base de los sistemas existentes, tales como el proceso de gobernanza para los planes nacionales de los Estados miembros en materia de energía y clima, los informes periódicos de la Agencia Europea de Medio Ambiente y los últimos datos científicos sobre el cambio climático y sus repercusiones. Además, aborda el camino a seguir para alcanzar el objetivo de 2050. La propuesta de Reglamento del Parlamento Europeo y del Consejo por el que se establece el marco para lograr la neutralidad climática y se modifica el Reglamento (UE) 2018/1999 (“Ley del Clima Europea”) se puede consultar en su versión española en https://eur-lex.europa.eu/legal-content/ES/TXT/HTML/?uri=CELEX:52020PC0080\&from=EN. El 19 de septiembre de 2020 se presentó una propuesta modificada del Reglamento cuya versión en inglés se puede consultar en https://ec.europa.eu/clima/sites/clima/files/eu-climate-action/docs/prop_reg_ecl_en.pdf

17 Esta revisión ya está en trámite y de hecho el 21 de septiembre de 2020 se cerró el periodo de información pública de la propuesta de Directiva, previendo su aprobación para el segundo trimestre de 2021. Esta propuesta de Directiva apuesta con más inten- 
REALA. Nueva Época - N.o 16, octubre 2021 - ISSN: 1989-8975 - DOI: https://doi.org/10.24965/reala.i16.10952 - [Págs. 71-97]

Cuestiones jurídicas sobre el papel de los entes locales en la transición energética: hacia la producción y el consumo del..

Carmen María Ávila Rodríguez

energética ${ }^{18}$; la propuesta de revisión del marco regulador de las infraestructuras energéticas, incluido el Reglamento RTE-E, para impulsar el despliegue de tecnologías e infraestructuras innovadoras, como las redes inteligentes, las redes de hidrógeno, la captura, el almacenamiento y el uso de carbono, y el almacenamiento de energía ${ }^{19}$.

Y entre las estrategias se aprueba Una nueva estrategia industrial para Europa ${ }^{20}$; Un nuevo plan de acción para la economía circular por una Europa más limpia y más competitiva ${ }^{21}$; la Comunicación de la Comisión al Parlamento Europeo, al Consejo, al Comité Económico y Social Europeo y al Comité de las Regiones del 3 de septiembre de 2020 Resiliencia de las materias primas fundamentales: trazando el camino hacia un mayor grado de seguridad y sostenibilidad 22 ; la Estrategia para una movilidad sostenible e inteligente, encaminando el transporte hacia el futuro ${ }^{23}$; la Estrategia de la UE para la integración del sistema energético ${ }^{24}$ y la Estrategia del hidrógeno para una Europa climáticamente neutra ${ }^{25}$.

En estas dos últimas estrategias mencionadas la prioridad de la Unión Europea es desarrollar el hidrógeno renovable utilizando principalmente para su producción energía eólica y solar. La elección del hidrógeno renovable se basa en la fuerza industrial europea en la producción de electrolizadores. De cara a 2050, el hidrógeno renovable se debe desplegar progresivamente a gran escala, paralelamente

sidad en promover un mayor desarrollo y uso de combustibles renovables y otros combustibles bajos en carbono, incluidos biocombustibles avanzados, combustibles líquidos y gaseosos sintéticos e hidrógeno, en sectores difíciles de descarbonizar, como la industria y el transporte pesado, la aviación y el transporte marítimo. La información relativa a esta revisión se puede consultar en inglés en https:// ec.europa.eu/info/law/better-regulation/have-your-say/initiatives/12553-Revision-of-the-Renewable-Energy-Directive-EU-2018-2001

18 El plazo de información pública se cerró también el 21 de septiembre y su aprobación se prevé igualmente para el segundo trimestre de 2021. La información relativa a esta revisión se puede consultar en inglés es https://ec.europa.eu/info/law/better-regulation/ have-your-say/initiatives/12552-Review-of-Directive-2012-27-EU-on-energy-efficiency

19 Vid. Jiménez-Blanco (2017, pp. 97-101).

20 El 10 de marzo de 2020, la Comisión sentó las bases de una estrategia industrial que impulsa la doble transición hacia una economía ecológica y digital, refuerza la competitividad industrial de la UE a nivel mundial y mejora la autonomía estratégica abierta de Europa. Al día siguiente de la presentación de la nueva estrategia industrial, la Organización Mundial de la Salud declaró la pandemia de COVID-19. Ante esta situación, la estrategia industrial ha tenido que ser actualizada (5 de mayo de 2021) y ahora ofrece nuevas medidas para tener en cuenta las enseñanzas extraídas de la crisis y apoyar la inversión. La denominación de la estrategia es Actualización de la nueva estrategia industrial 2020: Construir un mercado único más fuerte para la recuperación de Europa y el texto en inglés de la estrategia se puede consultar en el siguiente enlace: https://ec.europa.eu/info/sites/default/files/communication-industrial-strategy-update-2020_en.pdf

21 El 11 de marzo de 2020 se aprobó este Plan que presenta un conjunto de iniciativas interrelacionadas cuyo fin es establecer un marco sólido y coherente para la política de productos que convierta en norma la sostenibilidad de productos, servicios y modelos de negocio, además de transformar las pautas de consumo para evitar que se produzcan residuos en primer lugar. Este marco para la política de productos se irá desplegando progresivamente, mientras que las cadenas de valor de los productos clave se abordarán con carácter prioritario. Se adoptarán nuevas medidas para reducir la producción de residuos y garantizar que la UE disponga de un eficiente mercado interior de materias primas secundarias de alta calidad. Se reforzará también la capacidad de la UE para asumir la responsabilidad de sus residuos. El texto del Plan en español se puede consultar en https://eur-lex.europa.eu/resource.html?uri=cellar:9903b3256388-11ea-b735-01aa75ed71a1.0018.02/DOC_1\&format=PDF

22 El acceso a los recursos es una cuestión de seguridad estratégica para la ambición de Europa de sacar adelante el Pacto Verde. La nueva estrategia industrial para Europa propone reforzar la autonomía estratégica abierta de Europa, y advierte de que la transición de Europa hacia la neutralidad climática podría conllevar la sustitución de la actual dependencia de los combustibles fósiles por la dependencia de las materias primas, de las que nos abastecemos en gran medida del extranjero y para las que la competencia mundial es cada vez más feroz. Por lo tanto, la autonomía estratégica abierta de la UE en estos sectores debe basarse en un acceso diversificado y sin distorsiones a los mercados mundiales de materias primas, pero al mismo tiempo, y con el fin de reducir la dependencia exterior y las presiones ambientales, es preciso abordar el problema subyacente derivado del rápido crecimiento de la demanda mundial de recursos y para ello la UE pretende reducir el uso de materiales y reutilizarlos antes de reciclarlos. El texto de la Comunicación se puede consultar en https://eur-lex.europa.eu/legal-content/ES/TXT/PDF/?uri=CELEX:52020DC0474\&from=ES

23 Esta Estrategia se aprueba el 10 de diciembre de 2020 y en ella la Comisión propone reducir de aquí a 2050 un $90 \%$ las emisiones de $\mathrm{CO}_{2}$ causadas por el transporte. Para ello, el Ejecutivo europeo plantea cinco áreas clave de actuación: promover vehículos, buques y aviones sin emisiones; promover combustibles hipocarbónicos y renovables; ir hacia aeropuertos y puertos sin emisiones; conseguir una movilidad interurbana y urbana sostenible; e introducir mecanismos de tarificación del carbono. En cuanto al segundo pilar, la Comisión aspira a una movilidad inteligente y digital, que modernice el sistema de transportes, haciéndolo más seguro y eficiente. Para lograrlo, la Comisión proyecta dos áreas de actuación: fomentar una movilidad multimodal conectada y automatizada, e impulsar la innovación, el uso de datos e inteligencia artificial para la movilidad. Respecto al tercer pilar, la Comisión apuesta por impulsar modelos de movilidad más resilientes. Esta estrategia contiene, además, un anexo en el que establece un Plan de Acción, que detalla un total de 82 iniciativas y medidas concretas para cada una de ellas. La versión en inglés de la Estrategia se puede consultar en https://ec.europa. eu/transport/sites/transport/files/legislation/com20200789.pdf y la versión en inglés del anexo en https://ec.europa.eu/transport/sites/ transport/files/legislation/com20200789-annex.pdf

24 Esta estrategia se aprobó el 8 de julio de 2020 y en ella se prevé una serie de acciones para garantizar que la integración del sistema energético pueda contribuir al sistema energético del futuro, basado en la eficiencia, la resiliencia y la seguridad. El texto se puede consular en https://eur-lex.europa.eu/legal-content/ES/TXT/?uri=CELEX:52020DC0299

25 Esta estrategia se aprobó el 8 de julio de 2020. 
REALA. Nueva Época - N.o 16, octubre 2021 - ISSN: 1989-8975 - DOI: https://doi.org/10.24965/reala.i16.10952 - [Págs. 71-97]

Cuestiones jurídicas sobre el papel de los entes locales en la transición energética: hacia la producción y el consumo del...

al despliegue de la nueva generación de energía renovable, a medida que madura la tecnología y disminuyen los costes de sus tecnologías de producción. No obstante, a corto y medio plazo, se necesitan otras formas de hidrógeno con bajas emisiones de carbono, principalmente para reducir rápidamente las emisiones derivadas de la actual producción de hidrógeno y apoyar el uso paralelo y futuro del hidrógeno renovable.

En la resolución sobre la estrategia europea para el hidrógeno que el Parlamento europeo ha publicado el 19 de mayo de $2021^{26}$, éste pide a la Comisión que introduzca un marco regulador con criterios de sostenibilidad sólidos y transparentes para la certificación y el seguimiento del hidrógeno en la Unión, teniendo en cuenta su huella de gases de efecto invernadero a lo largo de toda la cadena de valor, incluido el transporte, con el fin de impulsar también inversiones en una generación de electricidad renovable adicional suficiente y le pide también que proporcione, lo antes posible en 2021, un marco reglamentario para el hidrógeno que garantice la normalización, la certificación, las garantías de origen, el etiquetado y la negociabilidad en todos los Estados miembros. Esta normativa tiene que completarse con un marco regulador coherente, integrado y global para un mercado del hidrógeno que supere los presentes obstáculos normativos y por ello reclama a la Comisión que elabore una hoja de ruta para el despliegue y el aumento de los electrolizadores, así como para forjar asociaciones a nivel de la Unión para garantizar su coste-efectividad, instando a la Comisión y a los Estados miembros a que eliminen las cargas administrativas existentes y a que incentiven la expansión de la cadena de valor y la introducción en el mercado del hidrógeno renovable para que esté maduro tecnológicamente y sea competitivo proporcionando estímulos financieros y sistemas de financiación específicos, incluidas soluciones innovadoras, como las primas de alimentación para el hidrógeno renovable introducido en la red de hidrógeno. Para ello será oportuno revisar las normas sobre ayudas estatales y los sistemas de tarificación y fiscalidad de la energía con vistas a internalizar los costes externos. De esta manera estima que el hidrógeno renovable podría ser competitivo antes de 2030, siempre que se formalicen las inversiones necesarias y un marco reglamentario adecuado que permitan que las energías renovables sean competitivas.

A la luz de lo analizado qué duda cabe que es necesaria la elaboración de un marco europeo normativo que establezca las directrices y homogeneice el mercado del hidrógeno.

\section{BARRERAS NORMATIVAS NACIONALES A SUPERAR PARA IMPULSAR EL HIDRÓGENO RENOVABLE}

En lógica secuencia con la política europea, el Gobierno de España elabora la Hoja de Ruta del Hidrógeno: una apuesta por el hidrógeno renovable que es aprobada el 6 de octubre de 2020 por el Consejo de Ministro. Este documento tiene su origen en lo dispuesto en el Plan Nacional Integrado de Energía y Clima (PNIEC) 2021-2030 que dedica su medida 1.8 al fomento de los gases renovables, citando expresamente el hidrógeno. La medida establece que se fomentará, mediante la aprobación de planes específicos, la penetración del hidrógeno expresando que éste tendrá un protagonismo considerable en la gestión de los vertidos renovables del sistema eléctrico. Resaltemos la importancia de que este reconocimiento se contenga en el PNIEC, pues es el instrumento de planificación propuesto por el Gobierno de España para cumplir con los objetivos y las metas de la Unión Europea en el marco de la política energética y climática, concretamente con la exigencia que impone el Reglamento (UE) 2018/1999 del Parlamento Europeo y del Consejo de 11 de diciembre de 2018 sobre la gobernanza de la Unión de la Energía y de la Acción por el Clima, y por el que se modifican los Reglamentos (CE) núm. 663/2009 y (CE) núm. 715/2009 del Parlamento Europeo y del Consejo, las Directiva 94/22/CE, 98/70/ CE, 2009/31/CE, 2009/73/CE, 2010/31/UE, 2012/27/UE y 2013/30/UE del Parlamento Europeo y del Consejo y las Directivas 2009/119/CE y (UE) 2015/652 del Consejo, y se deroga el Reglamento (UE) núm. 525/2013 del Parlamento Europeo y del Consejo. Esta normativa europea sienta la base legislativa de la Unión de la Energía y de la Acción por el Clima para asegurar el logro de los objetivos generales y los objetivos específicos de la Unión de la Energía, así como los compromisos de la Unión a largo plazo en materia de emisiones de gases de efecto invernadero, en consonancia con el Acuerdo de París de 2015. También persigue los objetivos establecidos en los diversos reglamentos y directivas sobre reducción de gases de efecto invernadero, eficiencia energética, energías renovables, diseño de mercado eléctrico y seguridad de suministro, así como las reglas

26 https://www.europarl.europa.eu/doceo/document/TA-9-2021-0241_ES.html\#def_1_17 
REALA. Nueva Época - N.o 16, octubre 2021 - ISSN: 1989-8975 - DOI: https://doi.org/10.24965/reala.i16.10952 - [Págs. 71-97]

Cuestiones jurídicas sobre el papel de los entes locales en la transición energética: hacia la producción y el consumo del...

Carmen María Ávila Rodríguez

de gobernanza para la propia Unión de la Energía. EI PNIEC es un documento programático que debe presentarse a la Comisión Europea para su evaluación ${ }^{27}$. EI BOE de 31 de marzo de 2021 publicó la Resolución de 25 de marzo de 2021, conjunta de la Dirección General de Política Energética y Minas y de la Oficina Española de Cambio Climático, por la que se publica el Acuerdo del Consejo de Ministros de 16 de marzo de 2021, por el que se adopta la versión final del Plan Nacional Integrado de Energía y Clima 2021-203028.

Volviendo al contenido de la Hoja de Ruta del Hidrógeno, contemplada en el marco del PNIEC, los objetivos que España se marca se han planificado para su ejecución en dos fases: una primera hasta 2030 y una segunda hasta 2050. De cara a 2030 los objetivos son los siguientes. En cuanto a la producción de hidrógeno renovable, se prevé la instalación en España de, al menos, 4 GW de potencia de electrolizadores que idealmente se localizarían para minimizar, los costes asociados al transporte y almacenamiento del hidrógeno renovable generado, en las proximidades de los lugares de consumo, ya sean industrias consumidoras de hidrógeno, hidrogeneras para su suministro u otras aplicaciones. En cuanto a la industria, se prevé una contribución mínima del hidrógeno renovable del $25 \%$ respecto del total del hidrógeno consumido en 2030 en todas las industrias consumidoras de hidrógeno tanto como materia prima como fuente energética. Respecto al transporte, se prevé que la cuota de energías renovables en el consumo final de energía sea, como mínimo, del $14 \%$ en 2030. Sin perjuicio de ello, el PNIEC establece una cuota más ambiciosa del $28 \%$. Para contribuir al cumplimiento de estos objetivos, se prevén los siguientes hitos: Flota de al menos 150-200 autobuses de pila de combustible de hidrógeno renovable en 2030 repartidos por todo el territorio nacional, con especial participación en las flotas de autobuses urbanos de ciudades de más de 100.000 habitantes; parque de al menos 5.000-7.500 vehículos ligeros y pesados de pila de combustible de hidrógeno para el transporte de mercancías en 2030; red de al menos 100-150 hidrogeneras de acceso público en 2030 para el repostaje de los vehículos antes mencionados. Estas deben situarse en lugares fácilmente accesibles, repartidas por todo el territorio con una distancia máxima de $250 \mathrm{~km}$ entre cada una de las hidrogeneras y la hidrogenera que tenga más próxima. Utilización en régimen continuo de trenes propulsados con hidrógeno renovable en al menos dos líneas comerciales de media y larga distancia en vías actualmente no electrificadas. Introducción de maquinaria de handling que utilice pilas de combustible de hidrógeno renovable y de puntos de suministro en los cinco primeros puertos y aeropuertos en volumen de mercancías y pasajeros respectivamente. En el sector eléctrico y el almacenamiento de energía se prevé la existencia de proyectos comerciales de hidrógeno renovable operativos en 2030 para el almacenamiento de electricidad y/o aprovechamiento de la energía renovable excedentaria según las orientaciones establecidas en la Estrategia de Almacenamiento 29.

De cara a 2050 se prevé un aumento considerable de la potencia renovable instalada en España a partir de 2030, que vendrá acompañada de una bajada de precios de la electricidad renovable y como consecuencia, la producción de hidrógeno mediante energía eléctrica renovable será competitiva frente a otras tecnologías de producción. Ello hará que la producción de hidrógeno renovable se incremente a gran velocidad y, al mismo tiempo, los avances tecnológicos y las economías de escala, harán posible una gran expansión del consumo de hidrógeno renovable en muchos sectores difíciles de descarbonizar ${ }^{30}$.

En clara consecución con el marco europeo antes analizado y como consecuencia de la implementación del PNIEC es necesario mencionar que España está llevado a cabo la aprobación de una serie de estrategias Así, se ha aprobado el 2 de junio de 2020 la Estrategia Española de Economía Circular para reducir la generación de residuos y mejorar la eficiencia en el uso de recursos; el 3 de noviembre de 2020 la Estrategia de Descarbonización a Largo Plazo, que marca la senda para alcanzar la neutralidad climática a 2050; el 9 de febrero de 2021 la Estrategia de Almacenamiento Energético que respalda el despliegue de energías renovables y será clave para garantizar la seguridad, calidad, sostenibilidad y economía del suministro ${ }^{31}$; y

27 Esta remisión fue acordada por el Consejo de Ministros el 31 de marzo de 2020.

28 El texto completo del Plan se puede consultar en https://www.boe.es/boe/dias/2021/03/31/pdfs/BOE-A-2021-5106.pdf

29 El despliegue de inversiones para la consecución de estos objetivos se estima por un valor de 8.900 millones de euros en la puesta en marcha de proyectos de producción de hidrógeno renovable y generación eléctrica renovable asociada, adaptaciones industriales y movilidad. Vid. Ministerio para la Transición Ecológica y el Reto Demográfico (2020, p. 42).

30 Vid. Ministerio para la transición ecológica y el reto demográfico (2020, p. 44). En este punto es necesario consultar la Estrategia a Largo Plazo para una Economía Española Moderna, Competitiva y Climáticamente Neutra en 2050. Esta estrategia fue aprobada por el Consejo de Ministros el 3 de noviembre de 2020 y se puede consultar en https://www.miteco.gob.es/es/prensa/documentoelp_tcm30-516109.pdf

31 Las estrategias se pueden consultar en https://www.miteco.gob.es/es/calidad-y-evaluacion-ambiental/temas/economia-circular/espanacircular2030_def1_tcm30-509532.PDF, https://www.miteco.gob.es/es/prensa/documentoelp_tcm30-516109.pdf y https:// www.miteco.gob.es/es/prensa/estrategiaalmacenamiento_tcm30-522655.pdf 
REALA. Nueva Época - N.o 16, octubre 2021 - ISSN: 1989-8975 - DOI: https://doi.org/10.24965/reala.i16.10952 - [Págs. 71-97]

Cuestiones jurídicas sobre el papel de los entes locales en la transición energética: hacia la producción y el consumo del...

Carmen María Ávila Rodríguez

están en elaboración: la Estrategia de autoconsumo ${ }^{32}$; la Hoja de Ruta para el desarrollo de la Eólica Marina y las Energías del Mar en España ${ }^{33}$ y la Hoja de Ruta del Biogás ${ }^{34}$.

La aprobación de estas estrategias y hojas de ruta debe ir acompañada de la oportuna creación de normas jurídicas que faciliten el cumplimiento de los objetivos que en las mismas se fijan. En la actualidad, la producción de hidrógeno está considerada como una actividad industrial al clasificarse como una industria química para la producción de un gas inorgánico, así se puede observar en el punto cuatro, del anexo I del Real Decreto 508/2007, de 20 de abril, por el que se regula el suministro de información sobre emisiones del Reglamento E-PRTR y de las autorizaciones ambientales integradas. Completando lo anterior, estas instalaciones requieren la autorización ambiental integrada como se prevé en el apartado 4.2,a) del anexo I del Real Decreto Legislativo 1/2016, de 16 de diciembre, por el que se aprueba el texto refundido de la Ley de prevención y control integrados de la contaminación. Pues bien, esta clasificación y estás exigencias ambientales están justificadas cuando la actividad se realiza en un contexto y volumen industrial a gran escala y con una producción de contaminantes $\left(\mathrm{CO}_{2}\right)$ elevada, de ahí que se restrinja la construcción de este tipo de infraestructuras en suelos calificados como industriales. Pero si la producción de hidrógeno se realiza a pequeña escala in situ (comercial o doméstica) y a través de un proceso como la electrolisis y sin apenas emisiones contaminantes de $\mathrm{CO}_{2}$, no es proporcionado. Es necesario que el legislador diferencie en el marco jurídico del hidrógeno el método de producción, la cantidad diaria producida, la capacidad del almacenamiento, y el propósito de dicha producción. En la medida en que un electrolizador tiene más similitudes con un transformador eléctrico que con una industria química debería permitirse la implantación de los mismos en todo tipo de suelos, precisamente para que puedan construirse planta de producción in situ cerca de plantas fotovoltaicas, parques eólicos, estaciones de servicio ubicadas en suelo urbano o incluso edificios para impulsarse el autoconsumo de los mismos. Sobre ello vamos a profundizar en las siguientes páginas.

Para cerrar este epígrafe, es interesante señalar que a nivel autonómico algunas Comunidades Autónomas están desarrollando sus propias estrategias de impulso del hidrógeno renovable. Así, Andalucía ya en 2016 publicó la Estrategia del Hidrógeno en Andalucía en el ámbito de la RIS3. Este documento recoge el potencial de la región y un plan de actuación para facilitar el desarrollo del hidrógeno en Andalucía. La Agencia Andaluza de la Energía (con participación directa en la Alianza Europea del Hidrógeno Limpio o el Partenariado Europeo del Hidrógeno) está coordinando a todos los actores de la cadena del hidrógeno de la región andaluza para llevar a cabo las actividades que aceleren su puesta en marcha en un período corto de tiempo ${ }^{35}$. La Comunidad valenciana en diciembre de 2020, junto a asociaciones y compañías del sector, firmó un protocolo de colaboración para el despliegue de la Estrategia Valenciana del Hidrógeno Verde, centrada en su producción a través de energía solar y eólica. La potenciación del hidrógeno verde, tanto en la generación como en su posterior uso industrial o movilidad, entre otros, forma parte del proyecto tractor de energía sostenible incluido en el documento de trabajo Estrategia Valenciana para la Recuperación ${ }^{36}$. Por su parte, Cataluña en el marco del Pacto Nacional para la Transición Energética de Cataluña, la Ley 16/2017 del Cambio Climático y la propuesta de Ley de la Transición Energética de Cataluña, está impulsando a través del Instituto Catalán de la Energía la Mesa del hidrógeno en la transición energética de Cataluña, formada por empresas, entidades y Administraciones para aportar propuestas específicas para el desarrollo del hidrógeno como vector energético ${ }^{37}$. Aunque Castilla y León tiene aprobada su propia Estrategia de Eficiencia Energética, no tiene aprobada una Estrategia específica para el hidrógeno, pero a través del Ente Regional de la Energía de Castilla y León pone de manifiesto el desarrollo de diversos proyectos con financiación pública relacionados con el hidrógeno en la región ${ }^{38}$. Por su parte, Castilla-La Mancha también puso en marcha en diciembre de 2020 el Cluster del Hidrógeno Verde, con sede en Puertollano donde además

32 La consulta previa para la elaboración de la Estrategia Nacional de Autoconsumo se abrió el 30 de julio de 2020 hasta el 18 de septiembre del 2020. Más información en https://www.miteco.gob.es/es/prensa/ultimas-noticias/-el-miteco-abre-la-consulta-previapara-la-elaboraci\%C3\%B3n-de-la-estrategia-nacional-de-autoconsumo/tcm:30-510885

33 La consulta previa para la elaboración de esta hoja de ruta se cerró el 5 de julio de 2020. Para más información se puede consultar en https://energia.gob.es/es-es/Participacion/Paginas/DetalleParticipacionPublica.aspx?k=316

34 La consulta previa para la elaboración de esta hoja de ruta se cerró el 5 de julio de 2020. Para más información se puede consultar en https://energia.gob.es/es-es/Participacion/Paginas/DetalleParticipacionPublica.aspx?k=315

35 Se puede consultar en https://www.juntadeandalucia.es/export/drupaljda/publicacion/18/11/Estrategia\%20del\%20Hidrogeno\%20en\%20Andalucia.pdf

36 Se puede consultar en https://www.gva.es/contenidos/publicados/multimedia/prensa/20201124/doc/201124_Propuesta_Estrategia_Valenciana_Recuperacion.pdf

${ }_{37}$ Se puede consultar en http://icaen.gencat.cat/es/participacio/taula-de-lhidrogen/

38 Más información se puede consultar en https://energia.jcyl.es/web/es/biblioteca/hidrogeno-pilas-combustible-castilla.html 
REALA. Nueva Época - N.o 16, octubre 2021 - ISSN: 1989-8975 - DOI: https://doi.org/10.24965/reala.i16.10952 - [Págs. 71-97]

Cuestiones jurídicas sobre el papel de los entes locales en la transición energética: hacia la producción y el consumo del..

se ubica la sede del Centro Nacional del Hidrógeno desde 200739. La Comunidad de Aragón ha creado la Fundación de Hidrógeno de Aragón que es un centro de investigación de carácter privado y sin ánimo de lucro cuyo fin último es el de promocionar el empleo del hidrógeno como vector energético, con el apoyo de la industria aragonesa y entidades de diferentes sectores de actividad ${ }^{40}$. Finalmente, Murcia, en noviembre de 2020, ha puesto en marcha la Mesa del Hidrógeno Verde de la Región de Murcia, con el objetivo de abordar la transición energética de la región ${ }^{41}$.

\section{LA ADMINISTRACIÓN LOCAL COMO SUJETO PROACTIVO EN LA TRANSICIÓN ENERGÉTICA}

En este epígrafe queremos poner de manifiesto cómo los Entes Locales tienen una posición privilegiada para ser las Administraciones públicas que concreten el impulso del hidrógeno renovable. Es sin duda un reto basado en que disponen de la competencia para hacerlo y pueden igualmente optar a fondos económicos que les permitan ser la Administración ejemplarizante en relación al impulso del hidrógeno renovable.

Aunque existen un sinfín de documentos europeos, nacionales y autonómicos, como hemos citado y cuyo análisis excede del objeto de nuestro estudio, vamos a partir de la Agenda Urbana Española 2019 para contextualizar el argumento de inicio de este epígrafe. La Agenda Urbana Española 2019 aprobada por el Consejo de Ministros el 22 de febrero de 2019, se enmarca en el Plan de Acción de la Agenda 2030 aprobado en junio de 2018 por el Gobierno de España. Ésta es un documento programático, no normativo, que recoge el conjunto de estrategias y acciones que se deben llevar a cabo para hacer de nuestros municipios lugares más justos y adaptados al cambio climático. Entre los objetivos que incluye y en relación al tema que nos ocupa, el impulso al hidrógeno renovable, la Agenda prevé una serie de objetivos entre los que vamos a citar aquellos que podemos clasificar en objetivos directamente vinculados al ámbito energético ${ }^{42}$ y los objetivos vinculados al ámbito de la movilidad sostenible.

Respecto a los primeros, es un objetivo de los Entes Locales apoyar la transición energética y una de las claves es la generación distribuida y el autoconsumo de energía en el ámbito urbano, así como promover la eficiencia energética a través de planes, estrategias y otras medidas, entre ellas: maximizar la prestación de los servicios de calefacción, refrigeración o iluminación, con el mínimo consumo posible, llevar a cabo medidas de prevención y resiliencia que prevengan y reduzcan al máximo los riesgos energéticos ( $v$. g., redes eléctricas que permiten el suministro alternativo, etc.); fomentar el uso de energías renovables térmicas, de manera especial en el parque edificatorio; fomentar el uso de la energía eléctrica en la medida en que permita contribuir a los objetivos de eficiencia energética y energías renovables; fomentar la generación distribuida de origen renovable, o generación in situ, es decir, contar con generación de energía por medio de variadas fuentes situadas en lugares lo más próximos posibles a las cargas; facilitar el autoconsumo en cubiertas municipales, mobiliario urbano, aparcamientos en superficie, etc., y la incentivación del autoconsumo en las cubiertas de edificios privados a través de medidas fiscales en el ámbito local (licencias de obra, IBI, etc.) y fomentar la contratación de servicios energéticos en los edificios públicos ${ }^{43}$.

Entre los objetivos relativos al ámbito de la movilidad sostenible es un objetivo de los Entes Locales: potenciar modos de transporte sostenible a través de la elaboración y aprobación de planes de movilidad urbana sostenible; fomentar los sistemas de transporte público eficientes; impulsar y favorecer el uso de vehículos de energías alternativas e híbridos; implantar puntos de recarga de coches eléctricos ${ }^{44}$.

No podemos olvidar que la excelencia del hidrógeno renovable reside en la posibilidad de producirlo en plantas locales, a partir de fuentes de energía renovables y en la posibilidad de almacenar esta energía para su uso posterior. Pero ¿qué competencias tienen los Entes locales para impulsar el hidrógeno renovable?

39 Más información se puede consular en https://www.castillalamancha.es/actualidad/notasdeprensa/el-gobierno-regional-seadhiere-al-cl\%C3\%BAster-del-hidr\%C3\%B3geno-de-castilla-la-mancha-y-da-un-paso-m\%C3\%A1s-en

40 Más información en https://hidrogenoaragon.org/es/ ALRSS $=1$

41 Más información en http://www.carm.es/web/pagina?IDCONTENIDO=109132\&IDTIPO=10\&RASTRO=c\$m122,70\&PORCAN

42 Sobre el papel de los Entes locales y la eficiencia energética consultar los siguientes estudios recientes: González (2021), Galán (2020c, pp. 233-254), Pérez (2020, pp. 433-439), Del Guayo (2013, pp. 287-300) y González (2015, pp. 201-228).

43 Vid. Agenda Urbana Española, Ministerio de Fomento (2019, pp. 117-118).

44 Vid. Agenda Urbana Española, Ministerio de Fomento (2019, pp. 126-127). 
REALA. Nueva Época - N.o 16, octubre 2021 - ISSN: 1989-8975 - DOI: https://doi.org/10.24965/reala.i16.10952 - [Págs. 71-97]

Cuestiones jurídicas sobre el papel de los entes locales en la transición energética: hacia la producción y el consumo del...

Carmen María Ávila Rodríguez

\subsection{Competencias propias de los municipios para impulsar el hidrógeno renovable: prestación de servicios obligatorios relacionados con la movilidad sostenible, la iluminación exterior y el saneamiento de aguas residuales}

No cabe duda que los Entes Locales tienen un fuerte protagonismo en la prestación de servicios públicos que pueden favorecer el impulso del hidrógeno renovable. No en vano, el artículo 25.2,b) contempla que ejercerá como competencias propias la materia de medio ambiente urbano, citando: en particular, parques y jardines públicos, gestión de los residuos sólidos urbanos y protección contra la contaminación acústica, lumínica y atmosférica en las zonas urbanas. También es competencia propia del municipio la movilidad y el transporte colectivo urbano, en virtud del artículo 25.2,g) de la LBRL Ello implica que se ejerce en régimen de autonomía y bajo la entera responsabilidad de la entidad local, y no admiten controles genéricos, sino específicos y de legalidad.

Estas competencias se atribuyen, fundamentalmente, por la legislación sectorial que dicta el Estado o las Comunidades Autónomas dentro de sus respectivos ámbitos de competencias determinados por el llamado bloque de constitucionalidad.

Por lo que se refiere a la legislación sectorial traigamos a colación, a modo de ejemplo, la recientemente aprobada Ley 7/2021, de 20 de mayo, de Cambio Climático y Transición Energética (en adelante LCCTE), en cuyo artículo 1 impone a las Entidades Locales, junto con la Administración General del Estado y las Comunidades Autónomas, la obligación de dar cumplimiento en el ámbito de sus respectivas competencias, al objetivo de esta ley, cooperando y colaborando para su consecución. El objetivo de la Ley es asegurar el cumplimiento, por parte de España, de los objetivos del Acuerdo de París, adoptado el 12 de diciembre de 2015, firmado por España el 22 de abril de 2016; facilitar la descarbonización de la economía española, su transición a un modelo circular, de modo que se garantice el uso racional y solidario de los recursos; y promover la adaptación a los impactos del cambio climático y la implantación de un modelo de desarrollo sostenible que genere empleo decente y contribuya a la reducción de las desigualdades. En cuanto a la movilidad sin emisiones y el transporte la ley en su artículo 14, impone a los Entes Locales que, en el marco de sus respectivas competencias, adopten medidas para alcanzar en el año 2050 un parque de turismos y vehículos comerciales ligeros sin emisiones directas de $\mathrm{CO}_{2}$, de conformidad con lo establecido por la normativa comunitaria. A estos efectos el PNIEC fija para el año 2030 que se alcanzará un parque de vehículos matriculados con nulas o bajas emisiones directas de $\mathrm{CO}_{2}$ de 5.000 .000 (turismos, furgonetas, autobuses y motos) ${ }^{45}$. Recordemos que la Hoja de Ruta del hidrógeno concreta en 2030 debe haber una flota de al menos 150-200 autobuses de pila de combustible de hidrógeno renovable repartidos por todo el territorio nacional, con especial participación en las flotas de autobuses urbanos de ciudades de más de 100.000 habitantes.

En este punto es interesante destacar que los entes locales son titulares de una flota operativa de vehículos y que en virtud de la Directiva 2009/3333/CE del Parlamento Europeo y del Consejo, de 23 de abril de 2009, relativa a la promoción de vehículos de transporte por carretera limpios y energéticamente eficientes imponía a los Estados, en su artículo 5, la obligación de garantizar que, a partir del 4 de diciembre de 2010, todos los poderes adjudicadores, las entidades adjudicadoras y los operadores, a la hora de comprar vehículos de transporte por carretera, tuvieran en cuenta los impactos energéticos y medioambientales que provoquen su utilización durante la vida útil del vehículo. La ley de contratos del sector público, como veremos, obliga a los entes públicos a que introduzcan criterios medioambientales y cláusulas en los contratos públicos que, en el ámbito que estudiamos, pueden favorecer la penetración progresiva del vehículo eléctrico en el parque vehicular de los Ayuntamientos y de las flotas municipales de servicios públicos como transporte colectivo, recogida de basuras. No podemos olvidar que en los municipios existe una importante flota de taxis y que para poder fomentar el tránsito del taxi vehículo convencional al taxi vehículo eléctrico también sería necesario aprobar una ordenanza municipal de taxi o modificar las existentes para incorporar entre otras medidas de promoción: la exención o reducción de las tasas que gravan la concesión o transmisión de licencias de taxi; establecer medidas de discriminación positiva en los concursos públicos abiertos para la ampliación del número de licencias en un municipio o simplificar los trámites administrativos en la sustitución

45 Vid. Ministerio para la Transición Ecológica y el Reto Demográfico (2020, pp. 140-143). La LCCTE impone también al Estado que se adopten las medidas necesarias, de acuerdo con la normativa de la Unión Europea, para que los turismos y vehículos comerciales ligeros nuevos, excluidos los matriculados como vehículos históricos, no destinados a usos comerciales, reduzcan paulatinamente

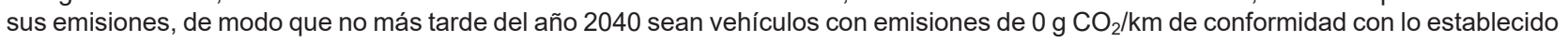
por la normativa comunitaria. 
REALA. Nueva Época - N.o 16, octubre 2021 - ISSN: 1989-8975 - DOI: https://doi.org/10.24965/reala.i16.10952 - [Págs. 71-97]

Cuestiones jurídicas sobre el papel de los entes locales en la transición energética: hacia la producción y el consumo del...

de un vehículo convencional por un vehículo eléctrico. Traigamos a colación el ejemplo del Ayuntamiento de Madrid en el que la Federación Profesional del Taxi de Madrid ha lanzado un proyecto para el reemplazo progresivo, hasta el año 2026, de al menos 1.000 taxis tradicionales por vehículos alimentados por hidrógeno verde. En el proyecto participa Fotowatio Renewable Ventures (FRV), parte de Abdul Latif Jameel Energy, uno de los líderes mundiales de energías renovables, que será la encargada de desarrollar toda la infraestructura de producción de hidrógeno renovable, recarga de los vehículos y suministro del combustible de la mano de Madrileña Red de Gas. Para ello, el proyecto contempla la construcción de un electrolizador de al menos $10 \mathrm{MW}$ alimentado por una planta solar fotovoltaica de $20 \mathrm{MW}$ que, conforme ascienda la demanda de hidrógeno renovable para más vehículos, podrán elevar su capacidad de producción. Por su parte, Toyota España será la compañía proveedora de los vehículos con el modelo Toyota Mirai ${ }^{46}$.

Orientado al objetivo de la transición energética, la LCCTE impone que antes de 2023 los municipios de más de 50.000 habitantes y los territorios insulares deben aprobar planes de movilidad urbana sostenible que introduzcan medidas de mitigación que permitan reducir las emisiones derivadas de la movilidad incluyendo, entre otras medidas fomentar el uso de medios de transporte eléctricos privados, incluyendo puntos de recarga y el establecimiento de zonas de baja emisión, entendiendo por zona de baja emisión el ámbito delimitado por una Administración pública, en ejercicio de sus competencias, dentro de su territorio, de carácter continuo, y en el que se aplican restricciones de acceso, circulación y estacionamiento de vehículos para mejorar la calidad del aire y mitigar las emisiones de gases de efecto invernadero, conforme a la clasificación de los vehículos por su nivel de emisiones de acuerdo con lo establecido en el Reglamento General de Vehículos vigente. La obligación de aprobar estos planes de movilidad urbana será también aplicable a los municipios de más de 20.000 habitantes cuando se superen los valores límite de los contaminantes regulados en Real Decreto 102/2011, de 28 de enero, relativo a la mejora de la calidad del aire. Otra medida que podría plantearse en el Plan de Movilidad sostenible sería aprobación de Ordenanzas de movilidad o modificación de las existentes para prever la discriminación positiva a la circulación de vehículos eléctricos con pila de hidrógeno en carriles especiales o en aquellas zonas donde se haya restringido el tránsito de los vehículos privados convencionales.

Al respecto del marco normativo en el que debería incardinarse el Plan de Movilidad Sostenible, tenemos que señalar que la disposición final octava de la LCCTE establece que, con objeto de reforzar y complementar el cumplimiento de las medidas de promoción de la movilidad sin emisiones, el Gobierno presentará a las Cortes Generales un proyecto de ley de movilidad sostenible y financiación del transporte. La inclusión de esta previsión en la Ley podemos valorarla positivamente pero, es necesario señalar que, aun así, llega tarde porque ya hay Comunidades Autónomas que tienen aprobada su normativa autonómica sobre movilidad e igualmente hay numerosos Ayuntamientos que han aprobado sus propias ordenanzas de movilidad, muy extensas en la mayoría de los casos, y todas esta normas se han aprobado con la ausencia de una normativa básica al respecto y que en caso de contradicción con la futura norma de movilidad estatal deberán ser reformadas.

No puede haber impulso a la movilidad sostenible sin infraestructuras de repostaje de vehículos limpios. Es por ello que la LCCTE regula las instalaciones de puntos de recarga en su artículo 15. Por un lado, prevé el derecho del público a disponer de la información de los puntos de recarga eléctrica para vehículos de acceso público, un año después de la entrada en vigor de la ley. Esta información se facilitará a través del Punto de Acceso Nacional de información de tráfico en tiempo real que está gestionado por el organismo autónomo Jefatura Central de Tráfico. Como contrapartida se impone la obligación a los prestadores del servicio de recarga eléctrica de remitir por medios electrónicos al Ministerio para la Transición Ecológica y el Reto Demográfico información actualizada de la localización, características, y disponibilidad de dichas instalaciones, así como del precio de venta al público de la electricidad o del servicio de recarga.

Por otro lado, a los titulares de las instalaciones de suministro de combustibles y carburantes se les impone también obligaciones en función del volumen anual agregado de ventas de gasolina y gasóleo $\mathrm{A}$. De este modo, aquellos cuyo volumen anual agregado de ventas de gasolina y gasóleo A en 2019 sea superior o igual a 10 millones de litros instalarán, deberán por cada una de estas instalaciones, disponer de al menos una infraestructura de recarga eléctrica de potencia igual o superior a $150 \mathrm{~kW}$ en corriente continua, que deberá prestar servicio en un plazo de veintiún meses a partir de la entrada en vigor de la ley. Aquellos cuyo volumen anual agregado de ventas de gasolina y gasóleo A en 2019 sea superior o igual a 5 millones de litros y menor a 10 millones de litros, instalarán, por cada una de estas instalaciones, al menos una infraestructura

46 Vid. https://portalmovilidad.com/madrid-marca-el-camino-con-1000-taxis-a-hidrogeno-verde-abastecidos-por-frv/ 
REALA. Nueva Época - N.o 16, octubre 2021 - ISSN: 1989-8975 - DOI: https://doi.org/10.24965/reala.i16.10952 - [Págs. 71-97]

Cuestiones jurídicas sobre el papel de los entes locales en la transición energética: hacia la producción y el consumo del...

Carmen María Ávila Rodríguez

de recarga eléctrica de potencia igual o superior a $50 \mathrm{~kW}$ en corriente continua, que deberá prestar servicio en un plazo de veintisiete meses a partir de la entrada en vigor de la ley.

La ley también prevé el caso de que en una provincia, Ciudad Autónoma o isla no exista ninguna instalación de suministro de combustibles y carburantes a vehículos cuyo volumen anual agregado de ventas de gasolina y gasóleo A en 2019 sea superior o igual a 5 millones de litros. En este caso quienes ostenten la titularidad de las instalaciones que, ordenadas de mayor a menor volumen de ventas anuales agregadas de gasolina y gasóleo, conjunta o individualmente alcancen al menos el $10 \%$ de las ventas anuales totales en las citadas áreas geográficas en el año 2019 deben instalar, por cada una de estas instalaciones, al menos una infraestructura de recarga eléctrica de potencia igual o superior a $50 \mathrm{~kW}$ en corriente continua, que deberá prestar servicio en un plazo de 27 meses a partir de la entrada en vigor de la ley.

A partir de 2021, quienes ostenten la titularidad de las instalaciones nuevas de suministro de combustible y carburantes a vehículos o que acometan una reforma en su instalación que requiera una revisión del título administrativo, independientemente del volumen anual agregado de ventas de gasolina y gasóleo de la instalación, deben instalar al menos una infraestructura de recarga eléctrica de potencia igual o superior a $50 \mathrm{~kW}$ en corriente continua, que deberá prestar servicio desde la puesta en funcionamiento de la instalación o finalización de la reforma de la misma que requiera una revisión del título administrativo.

Es interesante preguntarnos si este artículo se está refiriendo a los puntos de recarga de los vehículos eléctricos con pila de hidrógeno. A nuestro modo de ver no. Recordemos que el repostaje de un vehículo eléctrico con pila de hidrógeno se realiza en una hidrogenera que es el nombre que reciben las estaciones de repostaje de hidrógeno renovable. Esta infraestructura de repostaje sirve no sólo para turismos, autobuses o camiones que circulen por la vía pública, sino que también es necesaria para flotas cautivas como las carretillas elevadoras, trenes u otro tipo de vehículos especiales. El Marco de Acción Nacional de Energías Alternativas en el Transporte aprobado por el Real Decreto 639/2016, de 9 de diciembre, por el que se establece un marco de medidas para la implantación de una infraestructura para los combustibles alternativos, incluyó como objetivo alcanzar 20 hidrogeneras en 202047 . A pesar de esto, este plan no detalla los esfuerzos ni las medidas necesarias para cumplir este hito y quizá por ello, en 2018 tan sólo existían 5 hidrogeneras operando en España y además todas ellas en el marco de proyectos demostrativos financiados parcialmente por la UE y ninguna de ellas abiertas al público. Ha habido que esperar a 2021 para que se abra al público la primera hidrogenera en Madrid (se encuentra en la EESS San Antonio, a la altura del 34 de la Avenida de Manoteras). Se trata de una hidrógenera a 700 bares de presión (las 5 de uso privado eran de 350 bares). Esta hidrogenera se ha hecho posible a través de un proyecto conjunto de varias empresas: Enagás (vía Scale Gas), Toyota España, Urbaser, Carburos Metálicos, Sumitomo Corporation España y la Confederación Española de Empresarios de Estaciones de Servicio (CEEES) ${ }^{48}$. Es interesante traer en este punto el dato de que el PNIEC es consciente de la apenas apreciable incorporación de vehículos de pila de hidrógeno al parque móvil español (en 2020 se matricularon tan sólo 7 vehículos con pila de hidrógeno en toda España) ${ }^{49}$, esto es debido a que no existe la paridad de precio entre vehículos eléctricos con pila de hidrógeno y vehículos de combustión. Según estimaciones de los fabricantes, esta paridad se podrá alcanzar hacia el año 2025, debido al descenso esperado en el precio de las baterías. Es interesante señalar que los dos coches actuales a la venta con pilas de hidrógeno son el Toyota Mirai con un precio desde 69.000 euros y el Hyundai Nexo con un precio desde 72.850 euros $^{50}$. Como medida de fomento traigamos a colación que el Real Decreto 569/2020, de 16 de junio, por el que se regula el programa de incentivos a la movilidad eficiente y sostenible (Programa MOVES II) prevé la concesión de ayudas para la renovación del parque móvil y entre los modelos de vehículos susceptibles de ser incentivados, que deben figurar en la Base de Vehículos del Instituto para la Diversificación y Ahorro de la Energía (en adelante IDAE), se encuentran los dos modelos de coche antes mencionados ${ }^{51}$.

Volviendo a las infraestructuras de las hidrogeneras y su régimen jurídico, hay que destacar que el principal escollo al que se enfrenta un potencial operador de hidrogeneras es que, en España, todavía no se ha desarrollado legislación relativa a su diseño, permisos, construcción y operación, a diferencia de lo que

47 Vid. Entrena (2020).

$48 \mathrm{https://www.motor.es/noticias/abre-en-espana-la-primera-hidrogenera-de-alta-presion-esta-vez-abierta-al-publi-}$ co-202174893.html

49 https://www.motor.es/noticias/ventas-coches-hidrogeno-2020-diciembre-202174192.html

$50 \mathrm{https}: / / \mathrm{www}$.toyota.es/world-of-toyota/articles-news-events/new-toyota-mirai y https://www.hyundai.com/es/modelos/nexo.html

51 Esta base de datos se puede consultar en: http://coches.idae.es/base-datos/vehiculos-elegibles-programa-MOVES 
REALA. Nueva Época - N.o 16, octubre 2021 - ISSN: 1989-8975 - DOI: https://doi.org/10.24965/reala.i16.10952 - [Págs. 71-97]

Cuestiones jurídicas sobre el papel de los entes locales en la transición energética: hacia la producción y el consumo del...

ocurre con otras infraestructuras asociadas a los combustibles alternativos como el gas natural comprimido (GNC) o el gas licuado del Petróleo (GLP). En ausencia de un marco jurídico propio para las hidrogeneras, las Administraciones competentes tratan una potencial hidrogenera como un conjunto de instalaciones independientes para la producción de hidrógeno. El resultado de todo ello es un complejo procedimiento para obtener los permisos requeridos con requisitos desproporcionadamente restrictivos en materia ambiental y de seguridad. Una legislación específica de hidrogeneras tiene que tener en cuenta que las diferencias en los distintos tipos de producción de hidrógeno (electrolisis o reformado) así como sus diferentes aplicaciones y por tanto exigir adecuadas y proporcionadas evaluaciones de impacto ambiental.

En este marco legal desajustado una de las grandes posibilidades del hidrógeno renovable que es su producción in situ y que permitiría que las estaciones de repostaje de hidrógeno renovable lo produjeran in situ se hace realmente difícil en la práctica, pues existen barreras para su construcción, ya que conforme a los criterios de evaluación ambiental, las hidrogeneras con producción in situ son directamente consideradas como una industria química para la producción de gas inorgánico, sin importar el método de producción, la cantidad diaria y la capacidad de almacenamiento. Esta consideración restringe este tipo de infraestructura a ser construidas en suelo calificado como industrial, limitando así su implementación en otras ubicaciones como son las estaciones de servicio ya existentes. Es por ello una necesidad que el legislador revise estas situaciones, pues un electrolizador tiene más similitudes con un equipo eléctrico como puede ser un transformador que con una industria petroquímica al no tener asociadas emisiones contaminantes. Por esta razón, los estudios de impacto ambiental necesarios deben diferenciar entre producción de hidrógeno para usos industriales y para usos como vector energético a partir de la electrólisis.

En este punto es necesario señalar que el Ministerio de Industria, comercio y Turismo, formó un subgrupo de trabajo sobre tecnologías del hidrógeno y como resultado de sus trabajos en noviembre de 2019 elaboró un informe sobre la reglamentación actual y necesidades de desarrollo legislativo. En relación a las estaciones de servicio de hidrógeno renovable informaba que estaba en tramitación una modificación del Real Decreto 919/2006 que aprueba el reglamento sobre instalaciones de combustibles gaseosos en la que se amplía el ámbito de aplicación del mismo también al hidrógeno en fase gaseosa y también se estaba modificando la Instrucción Técnica Complementaria ITC-ICG 05 sobre estaciones de servicio para vehículos a gas, perteneciente al citado reglamento, con el fin de incluir el hidrógeno en fase gas para su utilización como carburante para vehículos a motor, de modo que exista una regulación básica de este tipo de estaciones de servicio que simplifique lo existente. Pues bien, estas modificaciones ya se han efectuado a través del Real Decreto 542/2020, de 26 de mayo, por el que se modifican y derogan diferentes disposiciones en materia de calidad y seguridad industrial.

Otra dificultad a tener en cuenta se refiere al almacenamiento y la distribución de hidrógeno renovable, pues, estas actividades deben cumplir muchas reglamentaciones al ser catalogado como peligroso y debe ser controlado permanentemente por autoridades reguladoras. Por ello se hace necesario normalizar entre otras cuestiones la infraestructura de almacenaje y distribución para las estaciones de servicio. El trabajo de estandarización en tecnologías del hidrógeno se lleva fundamentalmente a cabo a nivel internacional y en ella participa la Organización Internacional de Estandarización (ISO) que pueden ser asumidos, y de hecho lo son, como estándares europeos.

Respecto a las especificaciones técnicas, actualmente se aplican a las hidrogeneras: la Norma ISO/TS 20100 relativa al suministro de hidrógeno gaseoso; la Norma ISO 14687-2 relativa al grado de pureza que debe cumplir el hidrógeno y la Norma EN ISO 17268 relativa a los dispositivos de conexión para el suministro de hidrógeno gaseoso a vehículos de motor. Sin embargo, la Comisión Europea, avanzando un paso más hacia el impulso del hidrógeno, ha publicado un nuevo reglamento derivado de la directiva de combustibles alternativos ((UE) 2019/1745 de 13 de agosto de 2019), en el que se sustituyen algunas de las normas técnicas mencionadas. En concreto, la Norma EN 17127 relativa a puntos de recarga de hidrógeno al aire libre, en sustitución de la ISO/TS 20100, y que se complementaría con la ISO/TS 19880-1 sobre estaciones de servicio de hidrógeno gaseoso y la Norma EN 17124 relativa a especificación de producto y aseguramiento de la calidad, en sustitución de la ISO 14687-2. Estas nuevas normas serán de aplicación a partir del 12 de noviembre de 2021, siendo de aplicación a fecha de hoy las normas mencionadas en primer lugar.

Esperemos que estas reformas normativas, y las normas que deben aprobarse, sean las necesarias para la consecución de los objetivos que España se marca en la Hoja de Ruta para el hidrógeno según la cual se fija una red de al menos 100-150 hidrogeneras de acceso público en 2030 para el repostaje de los vehículos, situadas en lugares fácilmente accesibles y repartidas por todo el territorio con una distancia máxima de $250 \mathrm{~km}$ entre cada una de las hidrogeneras y la hidrogenera que tenga más próxima. En este sentido 
REALA. Nueva Época - N.o 16, octubre 2021 - ISSN: 1989-8975 - DOI: https://doi.org/10.24965/reala.i16.10952 - [Págs. 71-97]

Cuestiones jurídicas sobre el papel de los entes locales en la transición energética: hacia la producción y el consumo del...

son positivas las noticias como la publicada en febrero de este año en la que se anunciaba que la energética Naturgy ha presentado al Ministerio de Transición Ecológica, al de Industria y al de Ciencia un proyecto para la construcción de 38 hidrogeneras repartidas por España, teniendo 20 producción de hidrógeno renovable in situ en la instalación por medio de un electrolizador o una planta externa mientras las otras 18 serían sin producción in situ. Además se publicaba que estarían disponibles para el uso público en 2023 o $2024^{52}$.

Volviendo al artículo 15 de la LCCTE y como cláusula de cierre en relación a las infraestructuras de recarga de los vehículos eléctricos, éste fija en su apartado 10 que el Código Técnico de la Edificación establecerá las obligaciones relativas a la instalación de puntos de recarga de vehículo eléctrico en edificios de nueva construcción y en intervenciones en edificios existentes. Además, impone que antes del 1 de enero de 2023, todos los edificios de uso distinto al residencial privado que cuenten con una zona de uso aparcamiento con más de veinte plazas, ya sea en el interior o en un espacio exterior adscrito, deberán cumplir la exigencia relativa a las dotaciones mínimas para la infraestructura de recarga de vehículos eléctricos que establezca el Código Técnico de la Edificación. Reglamentariamente se regularán las obligaciones relativas a la instalación de puntos de recarga de vehículo eléctrico en aparcamientos no integrados en edificaciones.

Tan solo dos apuntes sobre otros servicios municipales que pueden favorecer el impulso del hidrógeno renovable. Los municipios deben prestar en todo caso el alumbrado público y el tratamiento de aguas residuales. Respecto al alumbrado público, esta competencia se encuentra reconocida en el artículo 26.1.a) para todos los municipios y en el apartado 2.f) para el caso de los municipios inferiores a 20.000 habitantes se concreta que a Diputación provincial o entidad equivalente coordinará su prestación. La eficiencia y el ahorro energético en el alumbrado exterior es un objetivo que se ha reglamentado en el Real Decreto 1890/2008, de 14 de noviembre, por el que se aprueba el Reglamento de eficiencia energética en instalaciones de alumbrado exterior y sus Instrucciones técnicas complementarias EA-01 a EA-07. Este Reglamento de carácter básico, establece las condiciones técnicas de diseño, ejecución y mantenimiento que deben reunir las instalaciones de alumbrado exterior para mejorar la eficiencia y el ahorro energético, disminuyendo el consumo de energía y por ende las emisiones de gases de efecto invernadero. Los entes locales han hecho un esfuerzo en la sustitución de sus lámparas convencionales a lámparas led, el siguiente paso podría ser utilizar un sistema que integrara la producción, almacenamiento y usos de las tecnologías del hidrógeno renovable para la iluminación. De esta forma se emplearía el excedente de energía eléctrica generado por paneles solares para la producción de hidrógeno mediante el proceso de electrólisis del agua, el gas se almacenaría para que cuando no haya sol, pueda ser utilizado para alimentar una celda de combustible y generar electricidad para aplicaciones de iluminación. En este sentido podríamos interpretar la previsión de la medida 2.9. prevista en el PNIEC relativa a la eficiencia energética en infraestructuras públicas en la que se prevé, entre otras, actuaciones de mejora de la eficiencia energética en infraestructuras de titularidad pública, principalmente, en las instalaciones de alumbrado público exterior para dar cumplimiento al objetivo de incrementar los niveles mínimos de eficiencia energética para los puntos de luz previsto en Real Decreto 1890/2008, de 14 de noviembre, antes mencionado ${ }^{53}$.

Otra competencia que tienen las Entidades locales es el tratamiento de aguas residuales, atribuida en el artículo 26.1 ,a) para todos los municipios y concretando el apartado 2, a) que aquellos de tengan una población inferior a 20.000 habitantes, la Diputación provincial o entidad equivalente coordinará la prestación. En particular, entre las actuaciones que realizan los municipios en materia de saneamiento destacamos: la elaboración de los proyectos de obras de las estaciones depuradoras de aguas residuales (en adelante EDARs); la ejecución de los proyectos de obras de las EDARs, financiando estos proyectos con cargo a sus fondos, así como su gestión que puede realizarse de forma conjunta con otros municipios. Es necesario aclarar que la titularidad municipal del servicio no implica que la gestión de las EDARs deba ser llevada a cabo por los Ayuntamientos directamente, pudiendo encomendarse estas competencias al sector privado y crear mancomunidades o consorcios que optimicen la prestación del servicio saneamiento. En este sentido, el artículo 44 de la LBRL reconoce a los municipios el derecho a asociarse con otros en mancomunidades para la ejecución en común de obras y servicios determinados de su competencia. Estas mancomunidades tienen personalidad y capacidad jurídica para el cumplimiento de sus fines específicos y se rigen por sus estatutos propios. A este respecto, el artículo 90 del Real Decreto Legislativo 1/2001, de 20 de julio, por el que se aprueba el texto refundido de la Ley de Aguas establece, en relación con las comunidades de usua-

52 https://www.lavanguardia.com/vida/20210209/6234172/naturgy-presenta-gobierno-proyecto-construir-38-hidrogeneras.html

53 Vid. Ministerio para la Transición Ecológica y el Reto Demográfico (2020, pp. 152 y 153). 
rios de vertidos, que las entidades públicas, corporaciones o particulares que tengan necesidad de verter agua o productos residuales, podrán constituirse en comunidad para llevar a cabo el estudio, construcción, explotaciones y mejora de colectores, estaciones depuradoras y elementos comunes que les permitan efectuar el vertido en el lugar más idóneo y en las mejores condiciones técnicas y económicas, considerando la necesaria protección del entorno natural. ¿Qué tiene que ver esto con el impulso del hidrógeno renovable? Es interesante señalar que investigadores de la Universidad de Barcelona, entre otras Universidades, han obtenido energía eléctrica e hidrógeno renovable de manera eficiente a partir del proceso de depuración de aguas residuales ${ }^{54}$. Éste sería un paso más hacia la transición a una economía circular, pues las aguas residuales son recursos que normalmente se desperdiciarían. Fabricar hidrógeno renovable a partir de materiales de desecho permite reutilizar el recurso hídrico y producir un combustible limpio a partir del biogás, al tiempo que se previenen las emisiones de gases de efecto invernadero ${ }^{55}$. Estas investigaciones abrirían la puerta a que estas infraestructuras públicas pudieran ser productoras de hidrógeno renovable para consumo propio o de terceros, pero ¿jurídicamente sería esto posible? Una primera respuesta la encontramos en el PNIEC en cuya medida 2.9. relativa a la eficiencia energética en infraestructuras públicas no solo se refiere a las instalaciones de alumbrado exterior, sino que adicionalmente, tiene por objetivo la mejora de la eficiencia energética de las instalaciones, entre otras, de depuración de aguas mediante la reforma de las instalaciones existentes y la introducción de criterios de eficiencia y bajo consumo energético en los pliegos de los concursos referentes a proyectos de potabilización.

\subsection{La responsabilidad proactiva de la Administración local: autoconsumo, contratación verde y constitución de comunidades energéticas locales}

La Estrategia del hidrógeno para una Europa climáticamente neutra se inspira en la directriz de democratización de la energía, que exige que Administraciones públicas, empresas y ciudadanos desempeñen un papel importante en la aplicación de una transición energética justa, exitosa, participativa e integradora; subraya, por tanto, la importancia de que todas las partes interesadas compartan los costes y los beneficios de un sistema integrado ${ }^{56}$. Esta democratización se deja sentir en la configuración de distintos conceptos, como «valles de hidrógeno» o "comunidades energéticas locales». Respecto a los primeros, la estrategia europea establece que se deben desarrollar agrupaciones de hidrógeno locales, como zonas remotas o islas, o ecosistemas regionales, denominadas «valles de hidrógeno», dependientes de la producción local de hidrógeno basado en la producción descentralizada de energía renovable y la demanda local, transportado a distancias cortas ${ }^{57}$. En tales casos, una infraestructura de hidrógeno específica puede utilizar hidrógeno no solo para aplicaciones industriales, de transporte, del equilibrio de la electricidad, sino también para el suministro de calefacción para edificios públicos, residenciales y comerciales. En este contexto ¿qué papel pueden adoptar los Ente Locales?

Pues bien, es este contexto, la responsabilidad proactiva de la Administración local se orienta a tres tipos de actuaciones: en primer lugar, el incremento del autoconsumo de energía renovables, el incremento de una contratación verde y en tercer la iniciativa de constituir comunidades energéticas locales.

\section{A) Incremento del autoconsumo de energías renovables de la Administración local y la posibilidad de producir hidrógeno renovable}

Para que la Administración local pueda impulsar el hidrógeno renovable, es imprescindible que se incremente la producción y el autoconsumo de energías renovables. El artículo 9 de la Ley 24/2013, de 26 de

54 Las aguas residuales contienen una gran cantidad de energía química almacenada en la materia orgánica contaminante. Para intentar aprovechar esta energía, investigadores de diferentes laboratorios de todo el mundo buscan cómo recuperarla, por ejemplo, en forma de hidrógeno, un proceso que eliminaría eficientemente la materia orgánica de las aguas residuales y permitiría no sólo la reducción del consumo energético del proceso de depuración sino, incluso, la obtención de energía a partir de este residuo. La clave para lograrlo son las llamadas celdas microbianas de electrólisis. Se trata de la utilización de unas bacterias muy especiales, las bacterias exoelectrógenas, que son capaces de oxidar la materia orgánica y generar corriente eléctrica permitiendo producir hidrógeno. En estas celdas basta con añadir un poco de energía en forma de voltaje, mucha menos de la necesaria para hacer la electrólisis del agua, que se recupera con creces en forma de hidrógeno, consiguiendo generación neta de energía. Vid. Blázquez et al. (2016).

55 Patel et al. (2020).

56 Vid. Ariño et al. (2020).

57 Vid. Comisión Europea (2020, p. 9). 
REALA. Nueva Época - N.o 16, octubre 2021 - ISSN: 1989-8975 - DOI: https://doi.org/10.24965/reala.i16.10952 - [Págs. 71-97]

Cuestiones jurídicas sobre el papel de los entes locales en la transición energética: hacia la producción y el consumo del...

diciembre, del Sector Eléctrico entiende por autoconsumo, el consumo por parte de uno o varios consumidores de energía eléctrica proveniente de instalaciones de producción próximas a las de consumo y asociadas a los mismos. La Ley diferencia dos modalidades de autoconsumo: el suministro con autoconsumo sin excedentes cuando los dispositivos físicos instalados impidan la inyección alguna de energía excedentaria a la red de transporte o distribución (en este caso existirá sólo el sujeto consumidor) y el suministro con autoconsumo con excedentes, cuando las instalaciones de generación puedan, además de suministrar energía para autoconsumo, inyectar energía excedentaria en las redes de transporte y distribución (en estos casos existirán dos tipos de sujetos: el sujeto consumidor y el productor) ${ }^{58}$.

Las entidades locales cuentan con numerosos edificios de usos muy variados y estos edificios, especialmente los de nueva construcción, que deberían ser edificios de consumo casi nulo (recordemos la obligación del artículo 9.1, b) de la Directiva 2010/31/UE el Parlamento Europeo y del Consejo, de 19 de mayo de 2010, relativa a la eficiencia energética de los edificios que obligaba a que a partir del 31 de diciembre de 2018 todos los edificios de titularidad pública de nueva construcción deberían ser de consumo casi nulo) ${ }^{59}$. Entre los emplazamientos (edificios de servicios y dependencias locales) más adecuados para la producción de energía renovable y autoconsumo podemos destacar los siguientes. En primer lugar, los colegios que, al tener un uso general por las mañanas hasta el mediodía, de lunes a viernes en otoño, invierno y primavera y dado que hay días sin uso, como los fines de semana, y horas al día de producción de energía no coincidente con el uso, como las tardes, parece aconsejables las instalaciones en la modalidad de autoconsumo con excedentes para que éstos puedan ser compensados. En segundo lugar, los edificios de servicios públicos (ayuntamiento y oficinas...) con la misma modalidad que los colegios. En tercer lugar, los polideportivos, pabellones cubiertos y piscinas climatizadas que suelen tener además de consumos eléctricos, demanda de energía térmica (agua caliente) por ejemplo para duchas. En cuarto lugar, las instalaciones de los servicios fundamentales y de urgencias (policía local, ambulatorio...) que tienen un consumo general de 24 horas al día, todos los días del año y por ello se hace recomendable no sólo tener instalaciones de autoconsumo sino también de almacenamiento. En quinto lugar, los edificios asignados a centros de transporte que sirven como parques de estacionamiento de autobuses urbanos. En estos casos, el montaje de una instalación renovable de autoconsumo, complementado con un electrolizador que produjera hidrógeno y permitiera la recarga de vehículos eléctricos, supondría un beneficio doble para el municipio, pues además de la producción de electricidad limpia para su autoconsumo se proporciona la habilitación de una flota de vehículos eléctricos para los servicios de transporte público. En sexto lugar, en las infraestructuras de titularidad local en los que se realiza el acopio de residuos sólidos urbanos y residuos de gestión del paisaje, podas y jardinería, o la depuración de aguas residuales, como hemos visto. Si éstas fueran de gestión local, sería conveniente analizar la viabilidad de instalaciones de energía renovables e instalaciones para producir hidrógeno renovable, bien para aprovechamiento térmico como para cogeneración (aprovechamiento térmico y eléctrico). El equipamiento de este tipo de centros no supone un excesivo consumo eléctrico, puesto que las actividades involucradas no suelen ir más allá del movimiento y almacenaje de materiales, de esta manera la generación eléctrica anual podría superar a la demanda, por ello la modalidad de autoconsumo con excedentes y venta de la energía eléctrica excedentaria podría ser el adecuado ${ }^{60}$. 0 bien podría el Ente Local elegir producir hidrógeno renovable para después consumirlo.

Pues bien, para que los entes locales puedan ver incrementada su capacidad de autoconsumo y puedan generar hidrógeno renovable, puesto que producido el hidrógeno por medio de electrólisis y antes de ser consumido por una pila de combustible para obtener de nuevo electricidad, es necesaria una etapa de almacenamiento intermedio para que este proceso tenga lugar; y teniendo también en cuenta que el artículo 6 de la LSE contempla la figura de titular de instalaciones de almacenamiento como la persona jurídica que posee instalaciones en las que se difiere el uso final de electricidad a un momento posterior a cuando fue generada, o que realizan la conversión de energía eléctrica en una forma de energía que se pueda almacenar para la subsiguiente reconversión de dicha energía en energía eléctrica, tendríamos que salvar un obstáculo: que estas instalaciones públicas se encuentran situadas en suelo urbano y que el hidrógeno es considerado desde un punto de vista legal y administrativo como un producto químico inflamable y peligroso en casi toda la Unión Europea que por tanto, como cualquier otro gas inflamable considerado en la reglamentación

58 Sobre el régimen jurídico del autoconsumo consultar los siguientes estudios: Leiva (2018, pp. 117-155), Leiva (2019, pp. 291334), Galán (2018b, pp. 215-240), Del Guayo et al. (2016, pp. 103-142) y González (2014, pp. 1623-1649).

59 Vid. García (2016, pp. 263-261) y González (2019, pp. 17-53).

60 Vid. Agencia Andaluza de la Energía (2020). 
aplicable de seguridad industrial en materia de almacenamiento de productos químicos, el lugar de almacenamiento debe estar ligado a unas condiciones y distancias de seguridad donde los depósitos son situados.

Es por ello que se hace necesario definir correctamente el significado de uso energético del hidrógeno renovable. Con el aumento de la utilización del hidrógeno renovable en diferentes aplicaciones comerciales y su consumo a partir de pilas de combustible, el almacenamiento de hidrógeno renovable debería estar permitido, con carácter general, en los lugares donde se produzca la demanda, incluyendo áreas residenciales. Sería necesario distinguir el uso industrial del hidrógeno del uso energético. El almacenamiento masivo de hidrógeno y sus aplicaciones deben seguir complejos procedimientos administrativos para obtener los permisos necesarios para su instalación y operación. Sin embargo, sus aplicaciones a pequeña escala como el autoconsumo energético con hidrógeno renovable o las estaciones de repostaje de hidrógeno renovable para pequeñas flotas, tendrían que estar asociadas únicamente a procedimientos simplificados para legalizar su instalación. Es necesario establecer un límite claro que distinga entre las aplicaciones a gran escala o industriales y las de pequeña escala para uso comercial o doméstico. Hay que adaptar la regulación y los trámites administrativos nacionales y locales para garantizar que el almacenamiento de hidrógeno renovable, en las cantidades en las que se requiera, se sitúe en las mismas zonas donde se encuentre o se puede ubicar la aplicación en la que se consume el hidrógeno renovable.

Salvados estos inconvenientes con las reformas legales oportunas, además del autoconsumo propio, Administraciones locales pueden fomentar el uso doméstico del hidrógeno renovable particular, a través de las bonificaciones fiscales que crea más convenientes dentro del marco del Real Decreto Legislativo 2/2004, de 5 de marzo, por el que se aprueba el texto refundido de la Ley Reguladora de Haciendas Locales. Estas bonificaciones deberían estar previstas en las ordenanzas fiscales. Así, por ejemplo, pueden incluir bonificaciones en el impuesto de bienes inmuebles, el impuesto sobre construcciones, instalaciones y obras (ICIO) y el impuesto de actividades económicas (IAE).

Igualmente, los Ayuntamientos pueden facilitar y agilizar los trámites administrativos necesarios para futura legalización de estas instalaciones. Por regla general, los ayuntamientos disponen de ordenanzas municipales en lo que se refiere a criterios urbanísticos para la protección de barrios o edificios antiguos, o de impacto visual de las edificaciones, destinadas a evitar la desfiguración de la perspectiva del paisaje o perjuicios a la armonía paisajística o arquitectónica, así como para la preservación y protección de los edificios, conjuntos, entornos y paisajes incluidos en catálogos o planes urbanísticos de protección del patrimonio. Estas normativas, a veces, pueden ser demasiado restrictivas, pues muchas de ellas fueron redactadas en épocas en las que las energías renovables apenas tenían penetración en la sociedad y se desconocían las posibilidades que presentan de localización en zonas no visibles de los edificios.

\section{B) El impulso de la contratación pública ecológica}

La contratación pública representa una gran proporción del consumo. Por tanto, desempeñar un papel en la consecución de objetivos de la economía circular y de los objetivos del paquete de energía y clima. Por ello la Comisión Europea quiere fomentar este papel a través de sus acciones sobre contratación pública ecológica, elaborando unos criterios a escala de la UE que posteriormente serán utilizados de forma voluntaria por las autoridades públicas. En primer lugar, la Comisión quiere asegurar que en el futuro se haga especial hincapié en aspectos pertinentes de la economía circular, como la durabilidad y la reparabilidad, al establecer o revisar los criterios de contratación. En segundo lugar, quiere apoyar un mayor uso de estos criterios por parte de las autoridades públicas, y reflexionar sobre el modo en que puede recurrirse a la contratación pública ecológica de modo más generalizado en toda la UE, en particular, en relación con los productos o los contratos muy pertinentes para la economía circular. Por último y a modo ejemplarizante, la Comisión quiere dar ejemplo, asegurándose de que la contratación pública ecológica se utiliza de la forma más amplia posible en su propia contratación, y reforzando el uso de la contratación pública ecológica en la financiación de la UE61 En este sentido se ha aprobado la Directiva (UE) 2019/1161 del Parlamento Europeo y del Consejo de 20 de junio de 2019 por la que se modifica la Directiva 2009/33/CE relativa a la promoción de vehículos de transporte por carretera limpios y energéticamente eficientes, que obligará a los poderes adjudicatarios de las administraciones públicas a disponer de un número mínimo de vehículos limpios en sus flotas.

61 Vid. Ministerio para la Transición Ecológica y el Reto Demográfico (2015). 
REALA. Nueva Época - N.o 16, octubre 2021 - ISSN: 1989-8975 - DOI: https://doi.org/10.24965/reala.i16.10952 - [Págs. 71-97]

Cuestiones jurídicas sobre el papel de los entes locales en la transición energética: hacia la producción y el consumo del...

Por su parte, la legislación española cuenta con un marco normativo que fomenta el uso de criterios de ahorro y eficiencia energética en los procedimientos de contratación de bienes, servicios y edificios por parte de las Administraciones Públicas ${ }^{62}$. Nos referimos a la Ley 9/2017, de 8 de noviembre, de Contratos del Sector Público, por la que se transponen al ordenamiento jurídico español las Directivas del Parlamento Europeo y del Consejo 2014/23/UE y 2014/24/UE, de 26 de febrero de 2014 (en adelante LCSP) y el Real Decreto-ley $3 / 2020$, de 4 de febrero, de medidas urgentes por el que se incorporan al ordenamiento jurídico español diversas directivas de la Unión Europea en el ámbito de la contratación pública en determinados sectores; de seguros privados; de planes y fondos de pensiones; del ámbito tributario y de litigios fiscales. En el ámbito de la Administración General del Estado, es necesario traer a colación la Orden PCl/86/2019, de 31 de enero, por la que se publica el Acuerdo del Consejo de Ministros de 7 de diciembre de 2018, por el que se aprueba el Plan de Contratación Pública Ecológica de la Administración General del Estado, sus organismos autónomos y las entidades gestoras de la Seguridad Social (2018-2025). Entre los objetivos podemos destacar: la adquisición por parte de la Administración pública de bienes, obras y servicios con el menor impacto medioambiental posible y la incorporación de cláusulas medioambientales en la contratación pública. El plan contempla que, de acuerdo con las competencias de la Administración General del Estado y con los criterios de contratación pública ecológica fijados por la Comisión Europea se consideran bienes, obras y servicios prioritarios, entre otros: la iluminación interior de edificios; el alumbrado público exterior y semáforos; los calefactores a base de agua; el diseño, construcción y gestión de edificios de oficinas; a electricidad; sistemas combinados de calor y electricidad; Sistemas de climatización y transporte. Ámbitos todos ellos en lo que la tecnología del hidrógeno renovable puede desplegar sus usos. Como ejemplo entre las principales especificaciones técnicas y/o criterios de adjudicación que pueden ser tenidos en cuenta por los órganos de contratación en el ámbito de los transportes el Plan prevé dar preferencia de adquisición, alquiler, renting u otras formas de uso de vehículos clasificados en el Registro de Vehículos de la Dirección General de Tráfico como «Cero Emisiones» o alternativamente «ECO» en aquellos casos en que no haya una alternativa "Cero emisiones» para la tipología de vehículo requerido y los usos a los que vaya a ser destinado, así como la inclusión de puntos de recarga para vehículos que utilicen energías alternativas (electricidad, gas natural, ...) en nuevas edificaciones y edificaciones existentes.

Una concreción de este impulso a la contratación pública ecológica la encontramos en la reciente LCCTE, en cuyo artículo 31 se prevé que de conformidad con la legislación de contratos LCSP en toda la contratación pública se deben incorporar de manera transversal y preceptiva criterios medioambientales y de sostenibilidad energética cuando guarden relación con el objeto del contrato. Estos criterios deberán ser respetuosos con los principios informadores de la contratación pública y figurar, junto con la ponderación que se les atribuya, en el pliego correspondiente. Para ello, la contratación de la Administración General del Estado y el conjunto de organismos y entidades del sector público estatal deben incorporar, de conformidad con el artículo 126.4 de la LCSP, como prescripciones técnicas particulares en los pliegos de contratación, criterios de reducción de emisiones y de huella de carbono dirigidos específicamente a la lucha contra el cambio climático. Para facilitar su práctica la Ley impone al Ministerio para la Transición Ecológica y el Reto Demográfico y al Ministerio de Hacienda, que, en el plazo de un año de su entrada en vigor, elaboren un catálogo de prestaciones en cuya contratación se tendrán en cuenta los criterios de lucha contra el cambio climático y en el que se identificarán tales criterios de reducción de emisiones y de huella de carbono. En todo caso, de conformidad con lo establecido en el artículo 201 de la LCSP, los órganos de contratación deben tomar las medidas pertinentes para garantizar que en la ejecución de los contratos los contratistas cumplen las obligaciones aplicables en materia medioambiental. Además de conformidad con lo dispuesto en el artículo 145.2 de la LCSP en las licitaciones de redacción de proyectos, de contratos de obra o concesión de obra se deben incluir entre los criterios de adjudicación: requisitos de máxima calificación energética de las edificaciones que se liciten; ahorro y eficiencia energética que propicien un alto nivel de aislamiento térmico en las construcciones, energías renovables y bajas emisiones de las instalaciones; medidas de reducción de las emisiones de gases de efecto invernadero y otros contaminantes atmosféricos en las distintas fases del proceso de construcción de obras públicas. Igualmente, en los contratos de arrendamiento en vigor de inmuebles, en los que la Administración General del Estado y el conjunto de organismos y entidades del sector público estatal sean la parte arrendataria, que no tengan la consideración de edificación con consumo

62 En relación a las cláusulas ambientales en la contratación del sector público, consultar los siguientes estudios recientes: Galán (2018a), Galán (2020a, pp. 269-313), Miranzo (2017, pp. 383-404), Fernández (2017, pp. 77-126), Sarasibar (2017, pp. 129-144), Razquin (2017, pp. 147-178) y López (2017, pp. 411-423). 
REALA. Nueva Época - N.o 16, octubre 2021 - ISSN: 1989-8975 - DOI: https://doi.org/10.24965/reala.i16.10952 - [Págs. 71-97]

Cuestiones jurídicas sobre el papel de los entes locales en la transición energética: hacia la producción y el consumo del...

Carmen María Ávila Rodríguez

de energía casi nulo conforme a la versión vigente a 31 de diciembre de 2020 del Código Técnico de Edificación, no podrán prorrogarse más allá de 2030, exceptuándose los contratos de arrendamientos sobre inmuebles radicados en el extranjero, que estarán regulados por la normativa de edificación y medioambiental vigente en el país en que se hallen situados.

No está demás resaltar en este momento que el PNIEC prevé distintas medidas que inciden en la política de la contratación ecológica. Así la Medida 2.11 relativa a la promoción de los servicios energéticos ${ }^{6}$. Recordemos que la figura de la empresa de servicios energéticos quedó incorporada al ordenamiento jurídico español mediante el Real Decreto-ley 6/2010, de 9 de abril, de medidas para el impulso de la recuperación económica y el empleo. Desde entonces, España ha aprobado planes y programas con el objetivo principal de promover la contratación de servicios energéticos por parte del sector público, como parte de la función de responsabilidad proactiva hacia el bien común que le corresponde. La reciente publicación de la guía de Eurostat sobre el tratamiento contable de los contratos de rendimiento energético (EPC o Energy Performance Contracts) ha permitido eliminar una de las barreras principales que dificultaban a las Administraciones Públicas la realización de inversiones para la rehabilitación energética de sus edificios (entre otras mejoras de la eficiencia energética posibles) en un escenario caracterizado por la necesidad de mantener el control del déficit público. EI PNIEC considera a las empresas de servicios energéticos parte del nuevo tejido empresarial necesario para la consecución de los objetivos de mejora de la eficiencia energética propuestos a 2030. De acuerdo con este principio, las diferentes Administraciones territoriales, a través de las agencias de energía, -ya sea el IDAE, como agencia de ámbito nacional, u otras de ámbito autonómico y local, deben promover nuevos modelos de contrato adaptados a las recomendaciones de Eurostat y conformes con la LCSP ${ }^{64}$ - O Otra de las medidas que se prevé en el PNIEC es la contratación de energías renovables (Medida 1.16) estableciendo que el conjunto de las Administraciones territoriales debe asumir una responsabilidad proactiva en materia de promoción de la eficiencia energética, liderando el proceso de transición energética hacia una economía descarbonizada en el año 2050. Recordemos que el Acuerdo Marco 23/2017 formalizado el 31 de julio de 2018 relativo al suministro de energía eléctrica en la Administración General del Estado, sus organismos autónomos, entidades gestoras y servicios comunes de la Seguridad Social y demás entidades públicas estatales, y otras adheridas, establece que el suministro de energía eléctrica tendrá un $50 \%$ de garantía de origen, salvo que en las prescripciones adicionales el organismo interesado haya establecido un porcentaje mayor. Por su parte, el Plan de Contratación Pública Ecológica y de la Administración General del Estado, antes mencionado fija el objetivo de contratación de energía eléctrica con origen $100 \%$ renovable en el año 2025, para todo el consumo eléctrico de los edificios y servicios de la Administración General del Estado. EI PNIEC es consciente de que para progresar más en la senda de descarbonización, es necesario promocionar similares objetivos en el resto de las Administraciones públicas, tanto autonómicas como locales, mediante la difusión de información, modelos de pliegos y licitaciones y manuales de buenas prácticas. Para ello, uno de los mecanismos que se concretan es el diseño e implementación de nuevos acuerdos marco de compra de energía $100 \%$ renovable, así como introducción de sistemas de autoconsumo renovable en los edificios públicos. Otra de las medidas que se prevén (medida 2.12) es la responsabilidad proactiva del sector público y la contratación pública eficiente energéticamente ${ }^{65}$. El PNIEC establece que, además de la contratación de energías renovables (Medida 1.16), el conjunto de las Administraciones territoriales debe asumir una responsabilidad proactiva en materia de promoción de la eficiencia energética, liderando el proceso de transición energética hacia una economía descarbonizada en el año 2050. Para ello como mecanismo concreto diseña que debe procederse a la renovación de 300.000 m²/año en la Administración General del Estado por encima del 3 \% exigido por la Directiva de Eficiencia Energética. De manera adicional, el cumplimiento de mejora de la eficiencia energética del 39,5\% en 2030 exige la adopción por parte del resto de las Administraciones territoriales de, al menos, el objetivo obligatorio para la Administración General del Estado, de renovación del $3 \%$ de la superficie edificada y climatizada del parque edificatorio público. En ese sentido, considera factible la renovación de $3.390 .000 \mathrm{~m}^{2} / a n ̃ o$ en edificios del parque público de las Comunidades Autónomas y Entidades Locales, para lo cual será necesario fomentar la cooperación entre los responsables de los edificios públicos. De manera singular para el parque edificatorio de la Administración General del Estado, se propone en el PNIEC, entre otras actuaciones, el fomento del autoconsumo y

63 Vid. Ministerio para la transición ecológica y el reto demográfico (2020, pp. 155 y 156).

64 Sobre la contratación pública y los servicios energéticos, consultar los siguientes estudios recientes: Castel (2020), Dopazo (2019, pp. 73-115), González (2017, pp. 179-208) y Román (2017, pp. 101-140).

65 Vid. Ministerio para la transición ecológica y el reto demográfico (2020, p. 156). 
REALA. Nueva Época - N.o 16, octubre 2021 - ISSN: 1989-8975 - DOI: https://doi.org/10.24965/reala.i16.10952 - [Págs. 71-97]

Cuestiones jurídicas sobre el papel de los entes locales en la transición energética: hacia la producción y el consumo del...

Carmen María Ávila Rodríguez

de la utilización de las energías renovables en los edificios públicos y de la contratación con empresas de servicios energéticos.

\section{C) Iniciativas para constituir comunidades energéticas locales}

Se pude afirmar que el término comunidades energéticas locales engloba dos conceptos cuales son las comunidades de energías renovables y las comunidades ciudadanas de energía. La Directiva 2018/2001 sobre fomento del uso de la energía procedente de fuentes renovables define la comunidad de energías renovables como una entidad jurídica que es titular de un proyecto de energías renovables que ha desarrollado y que se caracteriza porque los miembros que la integran son socios o miembros situados en las proximidades del proyecto, que participan en la misma abierta y voluntariamente, pudiendo ser personas físicas, pymes o autoridades locales. En cuanto a su finalidad primordial es proporcionar beneficios medioambientales, económicos o sociales a sus socios o miembros o a las zonas locales donde opera, en lugar de ganancias financieras. Entre las actividades que pueden realizar se encuentran la producción, el almacenamiento y la venta de energías limpias ${ }^{66}$. Aterrizando en su transposición los artículos 1.2 y 6 de la LSE prevén que estas entidades jurídicas puedan realizar las actividades destinadas al suministro de energía eléctrica y por tanto puedan producir, almacenar, vender energías renovables y así como prestar servicios de agregación u otros servicios energéticos. Un dato interesante al respecto es que, en el marco de lo dispuesto en la Directiva 2018/2001, las comunidades de energía renovable se asocian a la generación distribuida in situ para la producción de electricidad a partir de energías renovables; así, una de las actividades que están llamadas a desarrollar es el autoconsumo eléctrico, donde ya contamos con un marco normativo definido, como hemos visto. Pero también, podrían utilizarse para poner en marcha sistemas urbanos de calefacción y refrigeración o incluso para prestar otros servicios energéticos relacionados con la eficiencia energética.

Por su parte la Directiva 2019/944 sobre normas comunes para mercado interior de la electricidad se refiere a la comunidad ciudadana de energía como una entidad jurídica que se basa en la participación voluntaria y abierta y cuyo control efectivo lo ejercen socios o miembros que sean personas físicas, autoridades locales, incluidos los municipios, o pequeñas empresas que participa en la generación, incluida la procedente de energías renovables, la distribución, el suministro, el consumo, la agregación, el almacenamiento de energía, la prestación de servicios de eficiencia energética o, la prestación de servicios de recarga para vehículos eléctricos o de otros servicios energéticos a sus miembros o socios. La regulación de estas comunidades se realiza en el art. 16 de la Directiva, que ante la ausencia de un marco normativo específico para las mismas encomienda a los Estados miembros que aprueben un marco favorable que garantice entre otras cuestiones: que la participación en las mismas sea abierta y voluntaria; que los miembros tengan derecho a abandonarla; que se mantengan los derechos y obligaciones de los consumidores domésticos; sometimiento a procedimientos y tasas equitativos, proporcionados y transparentes, entre otras), que sirven para concretar la naturaleza jurídica de este tipo de entidades. En dicha ordenación favorable debe asegurarse que las comunidades ciudadanas de energía: puedan acceder a los mercados; reciban un trato no discriminatorio y proporcionado en las actividades que realicen; sean responsables de los desvíos que causen en el sistema eléctrico; en cuanto a la electricidad autogenerada se les considere como clientes activos y tengan derecho al reparto interno de la electricidad producida.

Puede concluirse que la principal diferencia entre ambas figuras por tanto es que, mientras el objetivo de la comunidad de energías renovables es la realización de proyectos de cualquier naturaleza (eléctrico, térmico o transporte) siempre y cuando el origen energético sea renovable, la comunidad ciudadana de energía se ha pensado para abarcar cualquier proyecto relacionado con el sector eléctrico, incluyendo la distribución, suministro, consumo, agregación, almacenamiento de energía, prestación de servicios de eficiencia energética o la prestación de servicios de recarga para vehículo eléctrico, o de otros servicios energéticos a sus miembros ${ }^{67}$.

En este contexto el Gobierno aprobó el Real Decreto-ley 23/2020, de 23 de junio, por el que se aprueban medidas en materia de energía y en otros ámbitos para la reactivación económica. que incorpora parcialmente, en lo relativo a las comunidades de energías renovables, la Directiva (UE) 2018/2001. Pre-

66 Sobre la iniciativa económica local, consultar los siguientes estudios: Huergo (2020, pp. 129-148), Galán (2020b, pp. 69-87), Ortega (2017, pp. 73-104), Lence (2015, pp. 179-214), Ortiz (2015, pp. 365-425), Del Guayo (2014, pp. 9-26), Montoya (2012, pp. 157202), Rivero (2011, pp. 14-29), Hurtado (1994) y Bordón (1991, pp. 141-178).

67 Vid. González (2020, pp. 147-193). 
REALA. Nueva Época - N.o 16, octubre 2021 - ISSN: 1989-8975 - DOI: https://doi.org/10.24965/reala.i16.10952 - [Págs. 71-97]

Cuestiones jurídicas sobre el papel de los entes locales en la transición energética: hacia la producción y el consumo del...

cisamente, incorpora la definición de las comunidades de energías renovables, tal y como están previstas en la Directiva mencionada, añadiendo el apartado j) del artículo 6.1 de la Ley 24/2013, de 26 de diciembre, del Sector Eléctrico. Del mismo modo, este Real Decreto Ley, añade el apartado 7.bis del artículo 14 de la Ley citada relativo a la fijación por el Gobierno del marco retributivo para la generación de energía eléctrica a partir de fuentes de energía renovable. El apartado añadido establece que en los procedimientos de concurrencia competitiva, orientados a la eficiencia en costes, se puede distinguir entre distintas tecnologías de generación en función de sus características técnicas, tamaño, niveles de gestionabilidad, criterios de localización, madurez tecnológica y aquellos otros que garanticen la transición hacia una economía descarbonizada, así como tener en cuenta las particularidades de las comunidades de energías renovables para que éstas puedan competir por el acceso al marco retributivo en nivel de igualdad con otros participantes.

EI PNIEC tiene numerosas referencias tanto a las comunidades energéticas renovables como a las comunidades energéticas locales. Así sitúa a las primeras que tienen que estar ligadas a las redes de climatización pues hay que garantizar una cuota mínima de energías renovables en el sector de usos térmicos con las cadenas de frío y calor ${ }^{68}$. Pero la referencia más extensa la podemos contemplar en la medida 1.13 que tiene por título comunidades energéticas locales y que prevé como principales actuaciones: desarrollar el marco normativo apropiado para definir estas entidades jurídicas y favorecer su desarrollo, en particular para cumplir con lo dispuesto en el artículo 22 de la Directiva 2018/2001 y en el artículo 16 de la Directiva 2019/944. Este desarrollo del marco normativo deberá tener en cuenta figuras y casuísticas de actores o agrupaciones existentes y susceptibles de constituirse en comunidades energéticas locales, como cooperativas, polígonos industriales, parques tecnológicos, comunidades de propietarios o zonas portuarias. Será por tanto necesario que se configure el régimen de constitución, el registro, así como legalización y adaptación de las entidades existentes al nuevo marco legal. Tengamos en cuenta que con el régimen jurídico vigente existen diversas fórmulas institucionales que pueden dar forma a este tipo de entidades (corporaciones de derecho público, sociedades mercantiles con participación público-privada, consorcios o cooperativas). Pero la coexistencia de personas físicas, autoridades locales, personas jurídicas, hacen también que en todas esas fórmulas haya elementos compatibles e incompatibles que dificultan la figura a elegir. El marco normativo que se apruebe tendrá que tener también en cuenta la eliminación de las barreras administrativas mediante el establecimiento de una ventanilla única que permita orientar al solicitante, actuando de facilitador de los procedimientos administrativos, así como la simplificación de trámites en los procesos vinculados a proyectos de comunidades energéticas locales.

Estas comunidades energéticas locales contribuirán a pasar de un modelo convencional, en el que la ciudadanía, las empresas y los ayuntamientos y entidades locales se limitaban a ser clientes, a un modelo más participativo, basado en energías renovables y abierto a nuevos actores. En definitiva, un modelo democratizado, más flexible, de producción cercana al punto de consumo, generador de actividad económica local y respetuoso con el entorno natural. La constitución de estas comunidades favorecerá el desarrollo del autoconsumo, la eficiencia energética, el aprovechamiento del espacio urbano para la generación renovable, una mayor concienciación energética y climática en la sociedad y el surgimiento de nuevos modelos de negocio. Incorporar el dato actual de que a finales del 2020 se abrió por el Ministerio para la Transición Ecológica y Reto Demográfico el proceso de consulta pública previa para el desarrollo de comunidades energéticas locales, que cerró el 2 de diciembre de 2020, y que tenía como finalidad recabar la opinión de colectivos y entidades interesadas sobre el planteamiento para la transposición de las directrices europeas con contenidos relacionados con Comunidades Energéticas Locales al ordenamiento jurídico español, la identificación de prioridades y principales retos, así como potenciales medidas para poder superarlos.

\section{A MODO DE COROLARIO}

El objetivo de alcanzar una economía descarbonizada en Europa para 2050 lleva a desarrollar e impulsar tecnologías respetuosas con el medio ambiente. La Unión Europea entre las directrices que está configurando quiere impulsar la tecnología del hidrógeno renovable para fortalecer el papel de la Unión Europea como líder en el Mercado del Hidrógeno que facilitará la transición a una economía justa.

68 Vid. Ministerio para la transición ecológica y el reto demográfico (2020, p. 96). 
REALA. Nueva Época - N.o 16, octubre 2021 - ISSN: 1989-8975 - DOI: https://doi.org/10.24965/reala.i16.10952 - [Págs. 71-97]

Cuestiones jurídicas sobre el papel de los entes locales en la transición energética: hacia la producción y el consumo del...

Para ello se requiere la aprobación de un cuerpo normativo que, partiendo de normas comunitarias transpuestas al ordenamiento interno a través de normas estatales que se desarrollen por normas autonómicas y concretadas en ordenanzas locales, regulen el hidrógeno renovable más allá de un elemento químico para concebirlo como un recurso energético. Estas normas deberán tener su oportuno complemento en los planes que a nivel estatal, autonómico y local sean necesarios para programar e implantar las medias de apoyo a la tecnología del hidrógeno renovable.

Entre todas las Administraciones territoriales, la Administración local puede y debe asumir un papel ejemplarizante en las medidas de eficiencia energética y transición hacia un modelo económico descarbonizado, no solo cumpliendo con la obligación de la contratación pública verde o ecológica, al igual que el resto de Administraciones públicas, o con el cumplimiento de las medidas de eficiencia energética en los edificios e instalaciones de su titularidad, sino que la consideración del hidrógeno renovable como un vector energético que permite su producción en los mismos lugares o lugares muy próximos a su consumo, que permite su almacenamiento para su posterior consumo, así como el aumento de la utilización del hidrógeno renovable en diferentes aplicaciones comerciales, hacen que las ciudades, y en muchas ocasiones su suelo urbano de uso residencial, se conviertan en el lugar oportuno para impulsar el mercado del hidrógeno que facilite la democratización energética.

Como consecuencia de ello la actuación de la Administración local debe evolucionar desde el carácter de prestadora de una serie de servicios que pueden incorporar la energía del hidrógeno renovable (piénsese en el servicio de transporte urbano colectivo a través de autobuses eléctricos con pila de hidrógeno) a proactora en el contexto energético no solo como autoconsumidora de energía renovable, sino como integrante de las comunidades de energías renovables y de las comunidades ciudadanas de energía que le permitan realizar las actividades destinadas al suministro de energía eléctrica y por tanto puedan producir, almacenar, vender energías renovables y así como prestar servicios de agregación u otros servicios energéticos.

Ahora bien, en este estudio hemos puesto de manifiesto que es necesario dotar a las Administraciones locales del cuerpo normativo preciso para poder impulsar el hidrógeno renovable. Así, tanto el legislador estatal como el legislador autonómico, cada uno de ellos en el marco de sus ámbitos competenciales, deberán aprobar y/o reformar las normas oportunas para distinguir el uso industrial del hidrógeno renovable del uso energético que permitan que sus aplicaciones a pequeña escala como el autoconsumo energético con hidrógeno renovable o las estaciones de repostaje de hidrógeno renovable para pequeñas flotas, estén asociadas únicamente a procedimientos simplificados para legalizar su instalación. Del mismo modo es necesario desarrollar el marco normativo apropiado para definir el régimen jurídico de las comunidades energéticas locales, en las que formen parte las autoridades locales (incluidos los municipios) aclarando las distintas figuras y la diversa casuística de actores o agrupaciones existentes y susceptibles de constituirse en comunidades energéticas locales, como cooperativas, polígonos industriales, parques tecnológicos, comunidades de propietarios o zonas portuarias. Será por tanto necesario que se configure el régimen de constitución, el registro, así como legalización y adaptación de las entidades existentes al nuevo marco legal.

\section{REFERENCIAS BIBLIOGRÁFICAS}

Alenza García, J. F. (2020). La economía circular en el Derecho ambiental. Actualidad Jurídica Ambiental, 102(2), 225-249 (ejemplar dedicado a: Congreso Homenaje a Ramón Martín Mateo «VIII Congreso Nacional Derecho Ambiental (Vulnerabilidad Ambiental)»). https://www.actualidadjuridicaambiental.com/wp-content/ uploads/2020/06/2020_06_Suplemento-102-2-Junio.pdf

Agencia Andaluza de la Energía (2020). Guía para el fomento del autoconsumo en los municipios andaluces. https:// www.agenciaandaluzadelaenergia.es/sites/default/files/Documentos/Guia_para_el_fomento_del_autoconsumo_ en_municipios_andaluces.pdf

Ariño Órtiz, G., Del Guayo Castiella, I. y Robinson, D. (2020). La transición energética en el sector eléctrico: líneas de evolución del sistema, de las empresas, de la regulación y de los mercados. Orkestra-Instituto Vasco de Competitividad.

Asociación Española del Hidrógeno (IDAE) (2008). 3. a Guía Inventario Sectorial del Hidrógeno y las Pilas de Combustible en España, Santiago de Compostela 2007. https://www.idae.es/uploads/documentos/ documentos_10760_3a_Guia_sectorial_Hidrogeno_y_Pilas_Combustible_08_edac888d.pdf

Ávila Rodríguez, C. M. ${ }^{a}$ (2021). Aspectos jurídicos del impulso del hidrógeno como materia prima, combustible y vector energético. Revista General de Derecho de los Sectores Regulados, 7. 
REALA. Nueva Época - N.o 16, octubre 2021 - ISSN: 1989-8975 - DOI: https://doi.org/10.24965/reala.i16.10952 - [Págs. 71-97]

Cuestiones jurídicas sobre el papel de los entes locales en la transición energética: hacia la producción y el consumo del...

Carmen María Ávila Rodríguez

Comisión Europea (2020, 8 de julio). Comunicación de la Comisión al Parlamento Europeo, al Consejo, al Comité Económico y Social Europeo y al Comité de las Regiones, Una estrategia del hidrógeno para una Europa climáticamente neutra. https://eur-lex.europa.eu/legal-content/ES/TXT/PDF/?uri=CELEX:52020DC0301\&from=ES

Blázquez, E., Gabriel, D., Baeza, J. A. y Guisasola, A. (2016). Treatment of high-strength sulfate wastewater using an autotrophic biocathode in view of elemental sulfur recovery. Water Research, 105, 395-405. https://doi. org/10.1016/j.watres.2016.09.014

Bordón Iglesias, E. (1991). La iniciativa económica local. En F. J. Villar Rojas (coord.) y J. M. de la Cuétara Martínez (dir.), Introducción a los servicios locales: Tipos de prestación y modalidades de gestión (pp. 141-178). INAP.

Castel Aznar, L. (2020). Ventajas de los contratos de servicios energéticos en pequeños municipios. Proceso y tramitación de un contrato ESE. Consultor de los ayuntamientos y de los juzgados: Revista técnica especializada en administración local y justicia municipal, 6.

Del Guayo Castiella, I. (2013). La situación de los entes locales ante el nuevo paradigma de sostenibilidad energética. En F. García Rubio y L. Mellado Ruiz (coords.), Eficiencia energética y derecho (pp. 287-300). Dykinson.

Del Guayo Castiella, I. (2014). Nuevo régimen jurídico de los servicios públicos locales, tras la Ley núm. 27/2013, de 27 de diciembre, de Racionalización y Sostenibilidad de la Administración Local. Revista de Estudios de la Administración Local y Autonómica. Nueva época, 2, 9-26. https://doi.org/10.24965/reala.v0i2.10190

Del Guayo Castiella, I., Domingo López, E. y Leiva López, A. D. (2016). Régimen jurídico del autoconsumo en España: A propósito del Real Decreto 900/2015, de 9 de octubre. En J. Castro-Gil Amigo (coord.), Riesgo regulatorio en las energías renovables (Vol. 2, pp. 103-142). Aranzadi Thomson Reuters.

Delgado Piqueras, F. (2011). El marco jurídico de la política energética europea, con especial referencia a la «electricidad verde». En L. I. Ortega Álvarez y S. de la Sierra Morón (coords.), Estudios de la Unión Europea (pp. 393-456). Universidad de Castilla-La Mancha.

Delgado Piqueras, F. (2020). Las energías renovables (electricidad verde) en la jurisprudencia de la Unión Europea. Actualidad Jurídica Ambiental, 102(2), 140-174 (ejemplar dedicado a: Congreso Homenaje a Ramón Martín Mateo «VIII Congreso Nacional Derecho Ambiental (Vulnerabilidad Ambiental)»). https://www.actualidadjuridicaambiental. com/wp-content/uploads/2020/06/2020_06_Suplemento-102-2-Junio.pdf

Dopazo Fraguío, P. (2019). Contratos de energía y PPAs (Power Purchase Agreements). Revista Aranzadi de derecho ambiental, 44, 73-115.

Egea Herrero, A. (2017). El futuro de las energías renovables y la eficiencia energética dentro de la política energética de la Unión Europea: el nuevo marco energético y climático para 2030/2050. En R. Galán Vioque e I. González Ríos (dirs.), F. López Ramón (pr.), Derecho de las energías renovables y la eficiencia energética en el horizonte 2020 (pp. 485-498). Aranzadi Thomson Reuters.

Entrena Ruiz, D. B. (2020). El suministro al por menor de combustible en el marco del desarrollo y la movilidad sostenibles. Revista General de Derecho de los Sectores Regulados, 6.

Escudero Gallego, R. y Martínez Garrido, S. (dirs.) (2019). Los objetivos mundiales de desarrollo sostenible. IberdrolaWolters Kluwer.

Expansión (2021, 28 de abril). BP, Iberdrola y Enagas preparan un proyecto de hidrógeno verde con inversiones de 160 milllones. https://www.expansion.com/valencia/2021/04/28/608945a1468aeb492a8b4596.html

Fernández Acevedo, R. (2017). Los retos ambientales de las nuevas directivas: la contratación pública como herramienta. En M. M. ${ }^{a}$ Razquin Lizarraga y J. F. Alenza García (coords.), Nueva contratación pública: mercado y medio ambiente (pp. 77-126).

Fernández de Gatta Sánchez, D. (2020). El ambicioso Pacto Verde Europeo. Actualidad Jurídica Ambiental, 101, 78109. https://www.actualidadjuridicaambiental.com/wp-content/uploads/2020/05/2020_05_12_Fdez-Gatta-PactoVerde-Europeo.pdf

Galán Vioque, R. (dir.) (2018a). Las cláusulas ambientales en la contratación pública. Editorial Universidad de Sevilla.

Galán Vioque, R. (2018b). El régimen del autoconsumo. En F. Delgado Piqueras e I. Gallego Córcoles (coords.), El derecho de las energías renovables y el regadío: Congreso sobre el Derecho de las Energías Renovables y el Regadío (pp. 215-240), Universidad de Castilla-La Mancha.

Galán Vioque, R. (2020a). Cláusulas ambientales: ¿Una moda o un nuevo elemento imprescindible de la contratación pública? En E. Díaz Bravo y J. A. Moreno Molina (dirs.), Contratación pública global: Visiones comparadas (pp. 269-313). Tirant lo Blanch-Universidad Santo Tomás.

Galán Vioque, R. (2020b). La progresiva apertura de los servicios públicos locales a la libre competencia. Revista de Estudios de la Administración Local y Autonómica. Nueva época, 14, 69-87. https://doi.org/10.24965/reala.i14.10854

Galán Vioque, R. (2020c). Un modelo energético sostenible para los entornos urbanos. En M. Moreno Linde (coord.) y D. J. Vera Jurado (dir.), Ciudad y territorio en el siglo XXI: reflexiones desde el Derecho Público (pp. 233-254). Universidad de Sevilla.

García Montoro, L. (2016). Objetivo 2020: de la eficiencia energética a los edificios de consumo de energía casi nulo. Revista CESCO de Derecho de Consumo, 19, 263-271. https://revista.uclm.es/index.php/cesco/article/view/1199

González Ríos, I. (2014). La incipiente regulación del autoconsumo de energía eléctrica: implicaciones energéticas, ambientales y urbanísticas. Revista Vasca de Administración Pública, 99, 1623-1649. https://doi.org/10.47623/ ivap-rvap.99.100.2014.068 
REALA. Nueva Época - N.o 16, octubre 2021 - ISSN: 1989-8975 - DOI: https://doi.org/10.24965/reala.i16.10952 - [Págs. 71-97]

Cuestiones jurídicas sobre el papel de los entes locales en la transición energética: hacia la producción y el consumo del..

Carmen María Ávila Rodríguez

González Ríos, I. (2015). El papel de los entes locales en el ahorro y la eficiencia energética (iluminación exterior, sector de la edificación y movilidad sostenible). En M. ${ }^{a}$ A. Torres López y J. Conde Antequera (coords.), Administración local y energías renovables (pp. 201-228). Comares.

González Ríos, I. (2017). Contratación pública y energía: el contrato de servicios energéticos y sus implicaciones jurídicas. En M. M. ${ }^{a}$ Razquin Lizarraga y J. F. Alenza García (coord.), Nueva contratación pública: mercado y medio ambiente (pp. 179-208). Aranzadi Thomson Reuters.

González Ríos, I. (2019). Los edificios de consumo casi nulo de energía: un reto para la protección ambiental, la diversificación energética y la rehabilitación urbana. Revista andaluza de administración pública, 103, 17-53. https://doi.org/10.46735/raap.n103.1073

González Ríos, I. (2020). Las «Comunidades energéticas locales»: un nuevo desafío para las entidades locales. Revista Vasca de Administración Pública, 117, 147-193. https://doi.org/10.47623/ivap-rvap.117.2020.04

González Ríos, I. (2021). Los entes locales ante la transición energética y la sostenibilidad energética. Aranzadi.

Gudín Rodríguez-Magariños, F. (2019). Economía circular en la Unión Europea: un marco jurídico global para el Derecho medioambiental del siglo XXI. Sepin-Servicio de Propiedad.

Huergo Lora, A. (2020). La prestación de los servicios públicos locales. Documentación Administrativa, 6, 129-148. https://doi.org/10.24965/da.i6.10768

Hurtado Orts, F. (1994). La iniciativa pública local en la actividad económica, Departamento de Publicaciones, FVMP, D. L.

Jiménez-Blanco y Carrillo de Albornoz, A. (2017). Las redes transeuropeas de transporte de energía. En R. Galán Vioque e I. González Ríos (dirs.), F. López Ramón (pr.), Derecho de las energías renovables y la eficiencia energética en el horizonte 2020 (pp. 97-101). Aranzadi Thomson Reuters.

Leiva López, A. D. (2018). La regulación del autoconsumo de electricidad en un nuevo entorno social y tecnológico. Revista Vasca de Administración Pública. Herri-Arduralaritzako Euskal Aldizkaria, 110, 117-155. https://doi. org/10.47623/ivap-rvap.110.2018.1.04

Leiva López, A. D. (2019). El prosumidor como pieza clave en la transición energética del sector eléctrico. Revista española de derecho administrativo, 200, 291-334.

Lence Reija, C. (2015). La iniciativa económica de las entidades locales y sus implicaciones para la libre competencia. Revista española de derecho administrativo, 170, 179-214.

López García, M. (2017). Eficiencia energética en la contratación pública: presente y previsiones de futuro en la normativa española. En R. Galán Vioque e I. González Ríos (dirs.), F. López Ramón (pr.), Derecho de las energías renovables y la eficiencia energética en el horizonte 2020 (pp. 411-423). Aranzadi Thomson Reuters.

Martín Pascual, E. (2020). El pacto verde europeo ¿posible salida verde de la crisis de la COVID-19? Revista General de Derecho Europeo, 51.

Ministerio de Fomento (2019). Agenda Urbana Española. Centro de publicaciones de la Secretaría General Técnica del Ministerio de Fomento. https://apps.fomento.gob.es/CVP/handlers/pdfhandler.ashx?idpub=BAW061

Ministerio para la Transición Ecológica y el Reto Demográfico (2015). Il Informe general sobre el estado de la contratación pública verde en la Administración General del Estado, sus organismos públicos y las entidades gestoras de la seguridad social. https://www.miteco.gob.es/es/ministerio/planes-estrategias/plan-de-contratacionpublica-ecologica/segundoinformegeneralsobreelestadodelacontratacionpublicaverdeenlaage_tcm30-88970.pdf

Ministerio para la Transición Ecológica y el Reto Demográfico (2020). Hoja de Ruta del Hidrógeno: una apuesta por el hidrógeno renovable. https://www.miteco.gob.es/es/ministerio/hoja-de-ruta-del-hidrogeno-renovable.aspx

Ministerio para la Transición Ecológica y el Reto Demográfico (2020). Plan Nacional Integrado de Energía y Clima (PNIEC) 2021-2030. https://www.miteco.gob.es/es/prensa/pniec.aspx

Miranzo Díaz, J. (2017). Los criterios de adjudicación ambientales en las directivas de 2014. En M. M. ${ }^{a}$ Razquin Lizarraga y J. F. Alenza García (coords.), Nueva contratación pública: mercado y medio ambiente (pp. 383-404). Aranzadi Thomson Reuters.

Montoya Martín, E. (2012). Título II. Los servicios y la iniciativa económicas locales. En E. Montoya Martín y S. Fernández Ramos (coords.), J. L. Rivero Ysern (dir.), Derecho local de Andalucía: la Ley 5/2010, de 11 de Junio de Autonomía Local de Andalucía (pp. 157-202). lustel.

Noceda, M. Á. (2021, 24 de mayo). Cummins se alía con Iberdrola para construir una planta de electrolizadores de hidrógeno verde en Guadalajara. El País. https://elpais.com/economia/2021-05-24/iberdrola-y-cumminsconstruiran-una-planta-de-electrolizadores-de-hidrogeno-verde-en-guadalajara.html

Ortega Bernardo, J. (2017). Servicios públicos e iniciativa económica local. En F. Velasco Caballero (dir.), Tratado de derecho económico local (pp. 73-104). Marcial Pons.

Ortiz García, M. (2015). La iniciativa económica local o la gestión de la común para el bien común. En F. García Rubio (coord.), Análisis de las repercusiones de la reforma local sobre la organización, competencias y servicios de las entidades locales (pp. 365-425). INAP.

Patel, S., Kundu, S., Halder, P., Marzbali, M. H., Chiang, K., Surapaneni, A. y Shah, K. (2020). Production of hydrogen by catalytic methane decomposition using biochar and activated char produced from biosolids pyrolysis. International Journal of Hydrogen Energy, 45(55), 29978-29992. https://doi.org/10.1016/j.ijhydene.2020.08.036 
REALA. Nueva Época - N.o 16, octubre 2021 - ISSN: 1989-8975 - DOI: https://doi.org/10.24965/reala.i16.10952 - [Págs. 71-97]

Cuestiones jurídicas sobre el papel de los entes locales en la transición energética: hacia la producción y el consumo del..

Carmen María Ávila Rodríguez

Pérez Andrés, A. A. (2020). Corrigiendo la vulnerabilidad ambiental en la ciudad. En E. Pérez de los Cobos Hernández (coord.), B. Soro Mateo, J. Jordano Fraga y J. F. Alenza García (dirs.), Vulnerabilidad ambiental y vulnerabilidad climática en tiempos de emergencia (pp. 433-439). Tirant lo Blanch.

Razquin Lizarraga, M. M. (2017). Mecanismos para la inclusión de cláusulas ambientales en los contratos públicos. En M. M. a Razquin Lizarraga y J. F. Alenza García (coords.), Nueva contratación pública: mercado y medio ambiente (pp. 147-178). INAP.

Rivero Ortega, R. (2011). ¿Cómo hacer sostenible la iniciativa económica local? Revista de estudios locales. Cunal, 137, 14-29.

Román Márquez, A. (2017). Eficiencia y ahorro energético en edificios e instalaciones públicas: los contratos de rendimiento energético. Revista andaluza de administración pública, 97, 101-140. https://doi.org/10.46735/raap. n97.77

Rosa Moreno, J. (2020). Requerimientos sectoriales del nuevo marco europeo de la energía renovable. Actualidad Jurídica Ambiental, 103, 41-78.

Ruiz Olmo, I. (2012). Electricidad verde en Europa: especial referencia al marco normativo de la energía fotovolcaica. Editorial Académica Española.

Ruiz Olmo, I. (2018). La autoproducción de energía fotovoltaica: su fomento en Estados Unidos y en la Unión Europea y su desincentivación en España. En F. Delgado Piqueras e I. Gallego Córcoles (coords.), El derecho de las energías renovables y el regadío (pp. 265-280). Congreso sobre el Derecho de las Energías Renovables y el Regadío, celebrado en la Facultad de Derecho de la Universidad de Castilla-La Mancha (Albacete), el 9 y 10 de noviembre de 2017. Universidad de Castilla-La Mancha.

Sarasibar Iriarte, M. (2017). Cláusulas ambientales en la contratación pública referencia al ciclo de la vida como criterio de adjudicación. En M. M. ${ }^{a}$ Razquin Lizarraga y J. F. Alenza García (coords.), Nueva contratación pública: mercado y medio ambiente (pp. 129-144). Aranzadi Thomson Reuters. 